\title{
Article \\ PDGF Receptor Alpha Signaling Is Key for Müller Cell Homeostasis Functions
}

\author{
Nundehui Díaz-Lezama ${ }^{1}$, Anne Wolf ${ }^{2} \mathbb{D}$, Susanne Koch ${ }^{1}$, Anna M. Pfaller ${ }^{1}$, Josef Biber ${ }^{1}$, Xavier Guillonneau ${ }^{3} \mathbb{D}$, \\ Thomas Langmann ${ }^{2}$ and Antje Grosche ${ }^{1, *}$
}

1 Department of Physiological Genomics, Biomedical Center, Ludwig-Maximilians-Universität München, D-82152 Planegg-Martinsried, Germany; nundehui.diaz_lezama@tu-dresden.de (N.D.-L.); Susanne.Koch@bmc.med.lmu.de (S.K.); Anna.Pfaller@bmc.med.lmu.de (A.M.P.); Josef.Biber@bmc.med.lmu.de (J.B.)

2 Laboratory for Experimental Immunology of the Eye, Department of Ophthalmology, Faculty of Medicine and University Hospital Cologne, University of Cologne, D-50931 Cologne, Germany; anne.wolf@uk-koeln.de (A.W.); thomas.langmann@uk-koeln.de (T.L.)

3 Institut de la Vision, INSERM, CNRS, Sorbonne Université, F-75012 Paris, France; xavier.guillonneau@inserm.fr

* Correspondence: Antje.Grosche@med.uni-muenchen.de

check for updates

Citation: Díaz-Lezama, N.; Wolf, A.; Koch, S.; Pfaller, A.M.; Biber, J.; Guillonneau, X.; Langmann, T.; Grosche, A. PDGF Receptor Alpha Signaling Is Key for Müller Cell Homeostasis Functions. Int. J. Mol. Sci. 2021, 22, 1174. https://doi.org/ 10.3390/ijms22031174

Academic Editor: Jan Wijnholds Received: 18 December 2020

Accepted: 21 January 2021

Published: 25 January 2021

Publisher's Note: MDPI stays neutral with regard to jurisdictional claims in published maps and institutional affiliations.

Copyright: (c) 2021 by the authors. Licensee MDPI, Basel, Switzerland. This article is an open access article distributed under the terms and conditions of the Creative Commons Attribution (CC BY) license (https:/ / creativecommons.org/licenses/by/ $4.0 /)$.

\begin{abstract}
Müller cells, the major retinal macroglia, are key to maintaining vascular integrity as well as retinal fluid and ion homeostasis. Although platelet derived growth factor (PDGF) receptor expression in Müller glia has been reported earlier, their actual role for Müller cell function and intimate interaction with cells of the retinal neurovascular unit remains unclear. To close this gap of knowledge, Müller cell-specific PDGF receptor alpha (PDGFR $\alpha$ ) knockout (KO) mice were generated, characterized, and subjected to a model of choroidal neovascularization (CNV). PDGFR $\alpha$ deficient Müller cells could not counterbalance hypoosmotic stress as efficiently as their wildtype counterparts. In wildtypes, the PDGFR $\alpha$ ligand PDGF-BB prevented Müller cell swelling induced by the administration of barium ions. This effect could be blocked by the PDGFR family inhibitor AC710. PDGF-BB could not restore the capability of an efficient volume regulation in PDGFR $\alpha$ KO Müller cells. Additionally, PDGFR $\alpha$ KO mice displayed reduced rod and cone-driven light responses. Altogether, these findings suggest that Müller glial PDGFR $\alpha$ is central for retinal functions under physiological conditions. In contrast, Müller cell-specific PDGFR $\alpha$ KO resulted in less vascular leakage and smaller lesion areas in the CNV model. Of note, the effect size was comparable to pharmacological blockade of PDGF signaling alone or in combination with anti-vascular endothelial growth factor (VEGF) therapy - a treatment regimen currently being tested in clinical trials. These data imply that targeting PDGF to treat retinal neovascular diseases may have short-term beneficial effects, but may elicit unwarranted side effects given the putative negative effects on Müller cell homeostatic functions potentially interfering with a long-term positive outcome.
\end{abstract}

Keywords: Müller cells; retina; PDGF receptor alpha; choroidal neovascularization; gliosis

\section{Introduction}

The effect of platelet-derived growth factor (PDGF) upon the stabilization of blood vessel integrity mediated via the activation of its specific receptors, PDGF receptor $\alpha$ (PDGFR $\alpha$ ) and $\beta$ (PDGFR $\beta$ ), was intensively investigated throughout the past years. These studies point to a central role of PDGF in recruiting pericytes to newly built blood vessels in the course of physiological angiogenesis during retinal development, but also in the context of pathological neovascularization as it occurs in diabetic retinopathy and age-related macular degeneration [1-4].The gold standard therapy of these diseases with medium-term success currently is the intravitreal injection of antibody derivates directed against vascular endothelial growth factor (VEGF; [5]). It has been proposed that treatment strategies 
combining anti-VEGF therapy with agents blocking PDGF signaling should be even more effective than the respective single treatment regimen [6,7]. The hypothesis behind it is that hindering PDGF signaling prevents pericyte-endothelial interactions in the process of neovessel formation, thereby reducing growth of the latter as well as associated problems such as scar formation, vascular leakage, and edema formation [8]. The aforementioned combinatory therapy has already been under investigation for its beneficial effects in clinical testing (e.g., phase III trials—https: / clinicaltrials.gov / identifiers: NCT01944839, NCT01940900, NCT01940887; [9]), but there remain several open questions regarding the effects of the anti-PDGF therapy at the cellular level. For example, it should be analyzed whether PDGF-similar to what was shown for VEGF [10]—is essential to the survival of different cell types of the retina. This kind of investigation allows for conclusions about putative (probably unwarranted) side effects of a long-term anti-PDGF therapy.

Immunofluorescence studies on the expression of PDGF-BB, PDGFR $\alpha$, and PDGFR $\beta$ suggest high expression levels in vascular and Müller cells [11-13]. Given that Müller cells are intimately interacting with pericytes and endothelial cells via perivascular processes [14,15], an intense PDGF-mediated crosstalk of these cellular entities in the course of angiogenesis and maintenance of vessel integrity is very likely. Supporting this assumption, Ikuno et al. [16] demonstrated that Müller cells could stimulate the proliferation of pericytes in vitro by secreting PDGF. That Müller cells are indeed essential to maintaining intact blood vessels was shown by Shen et al. [17] with an elegant transgenic mouse model that allows selective, time-controlled ablation of Müller cells in vivo. Loss of the latter leads to retinal disorganization, including vascular anomalies. Interestingly, in a human pathology-namely, idiopathic macular telangiectasia type 2-Müller cells appear to be absent from the central retina and there are speculations that the retinal edema associated with dilated, leaky vessels frequently found in the macula of these patients is due to the aforementioned Müller cell loss [18,19].

Several mouse models have been developed to investigate the functional role of PDGF signaling. Expression of binding-deficient PDGF-B instead of its intact counterpart resulted in malformed vessels with detached pericytes not getting into contact with the endothelial cells [20]. If PDGF was overexpressed, pericytes and endothelial and Müller cells were strongly proliferating, thereby promoting retinal degeneration [21-23]. However, even though expression of PDGF receptors on Müller cells was demonstrated years ago, almost nothing is known about the actual role of PDGF for Müller cell function and its interaction via this signaling pathway with other retinal cell types. Here we collected pioneer data about the role of PDGF signaling for Müller cells in vivo by use of a timecontrolled Müller cell-specific PDGFR $\alpha$ knockout in mice combined with a model of choroidal neovascularization, addressing the question of whether Müller cells contribute to the modulation of vascular integrity via PDGF signaling.

\section{Results}

\subsection{Induced Müller Cell-Specific Knockout of PDGFR $\alpha$}

From initial experiments, we determined that the Glast-CreER ${ }^{\mathrm{T} 2}$ construct drives very efficient Cre recombinase expression in mice crossbred with the Ai3 reporter line (Figure 1A, [24]). After recombination induced by tamoxifen administration, virtually every Müller cell expressed the reporter tdTomato. Importantly, reporter expression in other retinal cell types was not observed. This proved the usability of the Glast-CreER ${ }^{\mathrm{T} 2}$ construct to mediate Müller cell-specific knockout via the Cre recombinase system. To validate the efficiency of PDGFR $\alpha$ ablation in Müller glia, PDGFR $\alpha$ expression was detected via immunostaining. The vast majority of isolated Müller cells from PDGFR $\alpha$ KO mice was lacking immunoreactivity for PDGFR $\alpha$. In contrast, the Müller cell fraction obtained from wildtype littermates showed a strong expression of the receptor (Figure 1B). PDGFR $\alpha$ staining of Müller cell inner stem processes and vascular structures was observed in retinal cross-sections, which was largely absent from the PDGFR $\alpha$ KO retina (Figure S1). Next, we isolated RNA from retinal cell populations purified by magnetic activated cell 
sorting as described recently $[25,26]$ and performed quantitative real-time PCR (qPCR) to further evaluate the PDGFR $\alpha$ KO efficiency and specificity. Enrichment of the various retinal cell populations was validated on the basis of high expression levels of respective marker genes (Figure 1C). Even though there were some obvious cross contaminations, such as photoreceptors (marker gene neural retina leucine zipper, $n r l$ ) being present in the microglia and vascular cell populations, Müller cells (expressing the marker gene glutamine synthetase, $g l u l$ ), on which we focus here, were clearly purified and rather free from microglia (marker gene aif1) and photoreceptors ( $\mathrm{nrl}$ ) and at least partially separated from vascular cells expressing pecam 1 . In the end, the qPCR data confirmed a highly specific pdgfra expression in Müller cells compared to other retinal cell populations (Figure 1D). In line with the findings from the histological analysis, mRNA levels of Pdgfra were significantly lower in the Müller cell population from PDGFR $\alpha$ KO mice (about 30\% of the expression found in wildtypes). Importantly, the pdgfra transcript level in other retinal cell types was not affected by tamoxifen-induced Müller cell-specific PDGFR $\alpha$ knockout (Figure 1D). In sum, these results corroborated the cell type specificity and efficiency of the PDGFR $\alpha$ KO via the Glast-CreER ${ }^{\mathrm{T} 2}$ driver line.
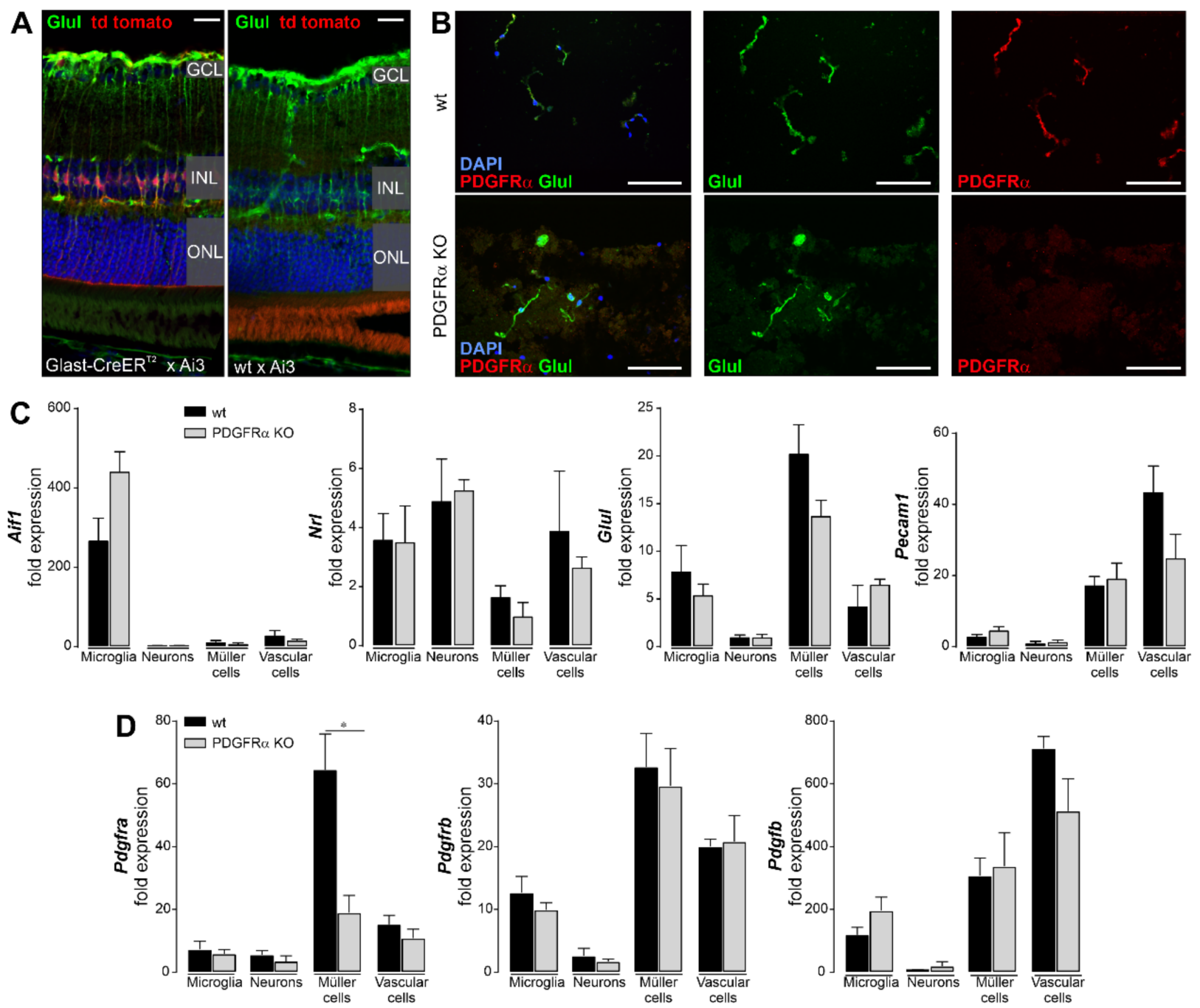

Figure 1. Validation of Müller cell-specific deletion of PDGFR $\alpha$ in tamoxifen-injected B6.Cg-Pdgfra ${ }^{\text {tm8Sor }} /$ EiJ; B6.Cg-Glast$\mathrm{CreER}^{\mathrm{T} 2}$ double transgenic mouse line 4 weeks post-injection. (A) Retinal cryosections from B6.Cg-Glast-CreER ${ }^{\mathrm{T} 2}$ mice that were crossbred with Ai3 mice [24]. The mice express tdTomato as the reporter for Cre recombinase activity. Note that tamoxifen injection led to expression of tdTomato in virtually every Müller cell (co-stained for the marker glutamine synthetase, Glul) and not in any other retinal cell type, demonstrating that the Glast-CreER ${ }^{\mathrm{T} 2}$ very efficiently and specifically drives expression of Cre recombinase in Müller glia. Scale bar, $20 \mu \mathrm{m}$. GCL, ganglion cell layer; INL, inner nuclear layer; 
ONL, outer nuclear layer. (B) Representative micrographs from Müller cells purified from retinae of respective genotypes and labeled for PDGFR $\alpha$ (red) and co-stained for the Müller cell marker glutamine synthetase (Glul, green). Note the absence of PDGFR $\alpha$ from Müller cells of B6.Cg-Pdgfra ${ }^{\text {tm8Sor }} /$ EiJ; B6.Cg-Glast-CreER ${ }^{\mathrm{T} 2}$ (PDGFR $\alpha$ KO mice) double transgenic mice. Nuclei were visualized by DAPI co-staining. Scale bars, $100 \mu \mathrm{m}$. (C) Validation of enrichment of various retinal cell populations for cell type-specific expression analysis via magnetic activated cell sorting. Marker genes for microglia (aif1), rods as the most abundant neuron of a mouse retina $(n r l)$, Müller cells $(g l u l)$, and vascular cells (pecam 1 ) were analyzed by quantitative real-time PCR (qPCR). (D) Knockout of PDGFR $\alpha$ was validated via qPCR on retinal cell populations purified by magnetic activated cell sorting. Pdgfra was specifically expressed by Müller cells and its expression was downregulated to $\sim 30 \%$ in Müller cells of PDGFR $\alpha$ KO mice. No effect on $p d g f r a$ expression levels was observed in the other retinal cell populations. Similarly, $p d g f r b$ and $p d g f b$ expression levels were not affected by Cre recombinase expression in Müller cells of PDGFR $\alpha$ KO mice. Bars represent mean \pm SEM and data were collected from 3-5 animals. ${ }^{*} p<0.05$.

Finally, we tested for potential expression changes of other components of the PDGF pathway upon PDGFR $\alpha$ knockout in Müller cells. Transcript levels of $p d g f r b$ and of the ligand $p d g f b$ showed no compensatory up- or downregulation in any retinal cell type (Figure 1D). Pdgfrb was expressed in a similar amount in microglia, Müller cells, and vascular cells, whereas Pdgfb was mainly expressed by vascular cells and at lower levels in Müller cells and microglia. Of note, PDGF signaling did not seem to directly involve retinal neurons, as they presented with very low expression levels of receptors and the ligand (Figure 1D).

\subsection{Normal Retinal Morphology in Müller Cell-Specific PDGFR $\alpha$ KO Mice}

To analyze whether the disruption of the PDGFR $\alpha$-related signaling in Müller glia affects retinal histology, we carefully evaluated the retinal phenotype in the Müller cellspecific PDGFR $\alpha$ KO mice. To assess the preservation of the retinal microarchitecture, morphometric analysis was performed (Figures 2 and S2). No differences regarding cell numbers quantified on the basis of DAPI staining for any of the three nuclear layers were found compared to the wildtype retinae (Figure 2B). In line with this, TUNEL labeling revealed that neither in wildtype nor in PDGFR $\alpha$ KO retinae did cells undergo DNA fragmentation as a sign of apoptotic cell death (Figure S2B). Subsequently, we immunolabeled sections with different neuronal markers such as anti-secretagogin (SCGN) to evaluate cone bipolar cells and their dendrites and anti-protein kinase- $\mathrm{C}-\alpha(\mathrm{PKC} \alpha)$ delineating rod bipolar and a subpopulation of amacrine cells (Figure 2A). SCGN- and PKC $\alpha$-positive bipolar cells did not show any kind of morphological abnormalities in the PDGFR $\alpha$ KO mouse. In addition, we analyzed the number of calretinin-positive ganglion and amacrine cells in the GCL and INL, respectively. We did not find any changes in number between the retinae from the two genotypes, and the three layers of dendrites of calretinin-positive cells in the IPL appeared normal (Figure 2A,C). Next, we evaluated a possible effect of the PDGFR $\alpha$ knockout on photoreceptor integrity. Cone arrestin and PDE6b (rods) immunostaining did not reveal any major morphological alterations of the two photoreceptor types (Figures 2A and S2A). The labeling pattern of glial fibrillary acidic protein (GFAP) was unchanged in PDGFR $\alpha$ KO mice. Accordingly, this marker delineated astrocytes in the nerve fiber layer, but no GFAP upregulation in Müller cells as a sign of gliotic changes was found (Figure 2A). Müller glia were additionally evaluated by immunostaining for glutamine synthetase to assess morphological alterations, but no differences were found when PDGFR $\alpha$ KO Müller cells were compared to their wildtype counterparts, either (Figure S2A). In addition, microglia, the resident tissue macrophages of the retina, did not display any morphological changes that would be indicative of their activation and, thus, of ongoing degenerative processes in the tissue (Figures 2A and S2C). Finally, we also investigated the integrity of the retinal pigment epithelium (RPE) through $\beta$-catenin immunostaining, which delineates RPE membranes. No apparent changes in staining intensities or a disruption of the RPE monolayer were found in the PDGFR $\alpha \mathrm{KO}$ mice (Figure S2D). 

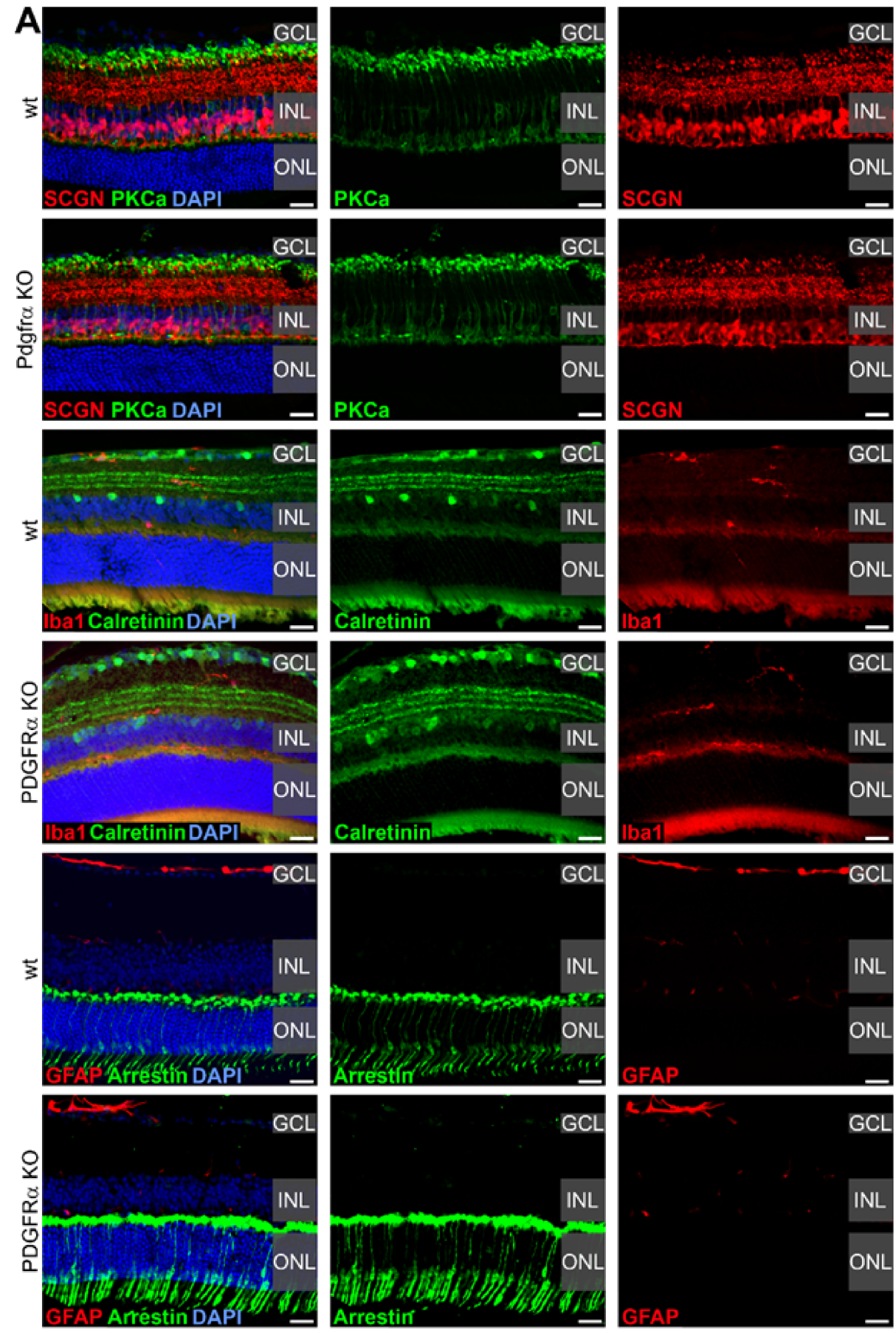

B

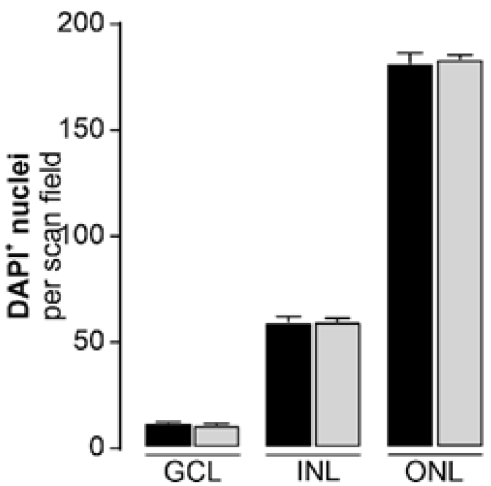

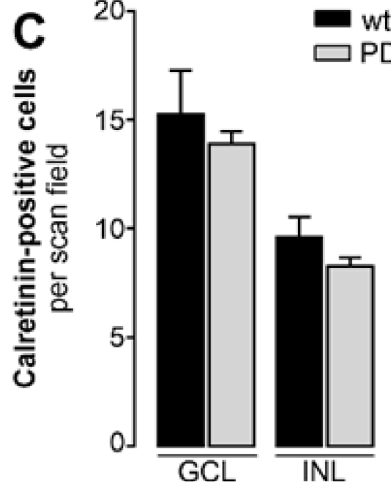

Figure 2. Characterization of retinal architecture in Müller cell-specific PDGFR $\alpha \mathrm{KO}$ mice. (A) Various retinal cell types in Müller cell-specific PDGFR $\alpha$ KO mice were characterized regarding 
cell counts and morphology to those of wildtype (wt) retinae using cell type-specific markers. Representative scans are shown. Specifically, cone bipolar cells (secretagogin, SCGN), rod bipolar cells $(\mathrm{PKC} \alpha)$, microglia (Iba1), ganglion and amacrine cells (calretinin), astrocytes and reactive Müller cells (glial fibrillary acidic protein, GFAP), and cones (arrestin) were examined. Nuclei were visualized by DAPI co-staining. Scale bars, $20 \mu \mathrm{m}$. ONL, outer nuclear layer. (B) Morphometric analysis was performed on central retinal slices of wt and PDGFR $\alpha$ KO mice. Cell numbers from the three nuclear layers were assessed by quantification of $\mathrm{DAPI}^{+}$nuclei. No difference could be observed between wt and PDGFR $\alpha$ KO retinae. Bars represent mean $\pm \mathrm{SEM}$ and data were collected from four animals of each genotype. (C) Central retinal sections stained for calretinin, a marker of amacrine cells in the inner nuclear layer (INL) and of ganglion and displaced amacrine cells in the ganglion cell layer (GCL), were used to quantify cell numbers between the different genotypes. Bars represent mean \pm SEM and data were collected from 3-5 animals of each genotype.

\subsection{Functional Disruption in Retinae of Müller Cell-Specific PDGFR $\alpha$ KO Mice}

The high expression level in Müller cells strengthened our assumption that PDGFR $\alpha$ might play a major role in their cellular functions. Accordingly, we addressed the effects of the knockout on Müller cell physiology directly. Recently, we demonstrated that growth factors such as VEGF acting via receptor tyrosine kinase receptors similar to PDGF are key for Müller cell volume regulation [27]. To test if PDGF acts in a comparable way on this Müller cell function, we measured their capability to counteract volume changes when subjected to hypoosmotic stress (Figure 3A). Typically, Müller cells do not swell under these conditions. However, if their potassium channels are blocked by the administration of barium ions, hypoosmotic stress immediately induces an increase in the Müller cell soma size, which is measured as an indicator for volume changes (Figure 3B). Co-application of PDGF-BB, a PDGFR $\alpha$ ligand, restored their efficient volume regulation in a dose-dependent manner (Figure 3B). This effect could be blocked by the rather unspecific PDGFR family inhibitor AC710 (Figure 3C). To circumvent drawbacks of unspecific pharmacological effects, we next checked whether knockout of PDGFR $\alpha$ would lead to disrupted Müller cell volume regulation. Indeed, PDGFR $\alpha$-deficient Müller cells swelled immediately even in the absence of any other tissue damage or channel blockers such as barium ions (Figure 3D). Growth factors such as VEGF induce a complex glutamatergic-purinergic signaling cascade fostering efficient Müller cell volume regulation [27]. Accordingly, we checked whether glutamate, known to act downstream of those growth factors and, thus, possibly also downstream of PDGFR $\alpha$, would reduce swelling in PDGFR $\alpha$-deficient Müller cells. Indeed, no swelling of Müller cells in knockout retinae was observed upon glutamate administration under hypoosmotic conditions (Figure 3D).

In addition to the growth factor-induced glutamatergic-purinergic signaling cascade, the inwardly rectifying potassium channel Kir4.1, as well as the water channel protein aquaporin-4 (AQP4), were implicated in osmotic volume regulation in Müller cells [28-30]. If the absence of PDGFR $\alpha$ were to change their expression or spatial distribution, this could be an alternative explanation for our finding of disturbed Müller cell volume regulation. However, Müller cell-specific PDGFR $\alpha$ knockout retinae displayed a normal localization of Kir4.1 and AQP4 primarily in Müller cell end feet lining the inner retinal surface towards the vitreous, and in their processes, enwrapping blood vessels (Figure 3E). The intensity of the immunostaining was comparable between knockout and wildtype retinae. Altogether, these data suggest that (i) PDGF-mediated signaling is involved in Müller cell volume regulation and (ii) that PDGFR $\alpha$ deficiency cannot be compensated by PDGFR $\beta$, at least not in the context of Müller cell volume regulation. 

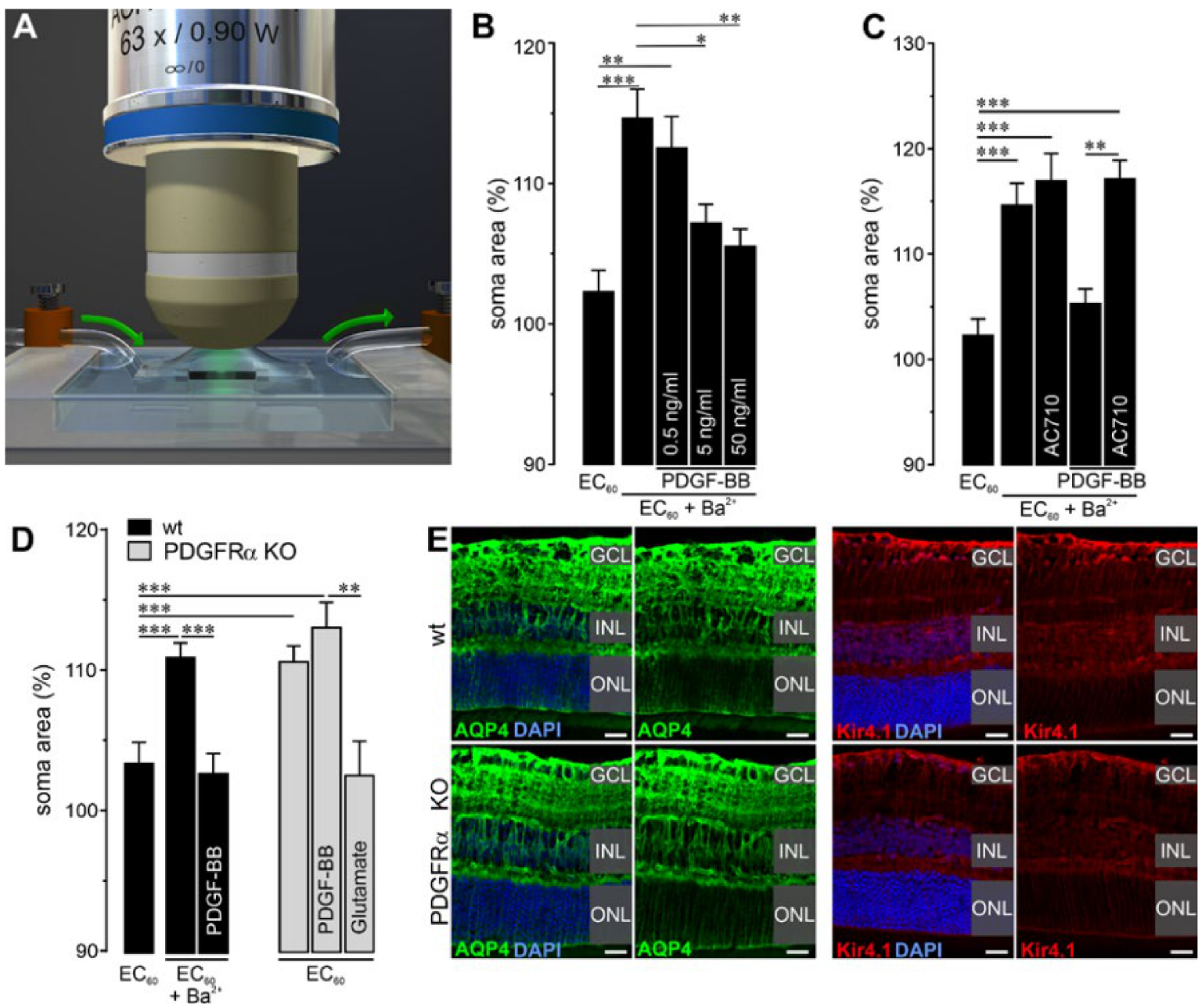

Figure 3. Dysfunctional volume homeostasis in PDGFR $\alpha$-deficient Müller cells. (A) Scheme of the experimental setup to determine Müller cell volume regulation. Vital retinal slices were stained with Mitotracker Orange and were examined via confocal scanning microscopy while hypotonic solution was washed into the recording chamber. (B) In wildtype Müller cells, PDGF-BB showed a dose-dependent effect, preventing the swelling of Müller cells induced by the co-application of barium ions $\left(1 \mathrm{mM}, \mathrm{Ba}^{2+}\right)$ and exposure to $4 \mathrm{~min}$ of hypoosmotic stress (60\% osmolarity). (C) AC710, a potent PDGFR family inhibitor $(100 \mu \mathrm{M})$, abolished the protective action of PDGF-BB (50 ng/mL) in Müller cells from wildtype animals. (D) In the absence of PDGFR $\alpha$, Müller cells were not able to counterbalance volume changes under hypoosmotic stress as efficiently as their wildtype counterparts. Administration of the PDGFR $\alpha$ ligand PDGF-BB (50 ng/mL) did not prevent cell volume changes in Müller cell-specific PDGFR $\alpha$ KO retinae. In contrast, glutamate $(1 \mathrm{mM})$ efficiently blocked cell swelling of PDGFR $\alpha$-deficient Müller cells under hypoosmotic stress. Experiments on wildtype littermates were repeated, combining barium ions and PDGF-BB to demonstrate no adverse effect of tamoxifen treatment on key findings observed in (C). (B-D) Bars represent mean \pm SEM and data were collected from 15-34 cells isolated from 2-3 animals of each genotype. ${ }^{*} p<0.05,{ }^{* *} p<0.01 ;{ }^{* * *} p<0.001$. (B) ${ }^{*}$ Changes in soma were tested after 4 min of exposure to hypoosmolar $(60 \%$ osmolarity) extracellular solution (EC 60 ) with a Mann-Whitney U-test. (E) Representative images of immunofluorescent detection of the water channel aquaporin 4 (AQP4) and the potassium channel Kir4.1 in Müller cell-specific PDGFR $\alpha$ KO retinae and wildtypes. Both proteins were enriched in Müller cell end feet facing the vitreous and blood vessels. There was no discernible phenotype in terms of immunoreactivity or distribution of Kir4.1 and AQP4. GCL, ganglion cell layer; INL, inner nuclear layer; ONL, outer nuclear layer. Scale bars, $20 \mu \mathrm{m}$.

Given our finding that Müller cell volume regulation was impaired in PDGFR $\alpha$ KO mice, we asked whether as a consequence retinal function would also be altered in those mice. Indeed, we found considerable functional deficits in the retinal light responses of Müller cell-specific PDGFR $\alpha$ KO mice as determined by electroretinogram (ERG) recordings (Figure 4A). Under dark-adapted conditions with dim flashes, to derive rod responses, 
a rod-specific b-wave (positive deflection) was recorded. The rod-driven b-wave amplitude was reduced in PDGFR $\alpha$ KO mice compared to wildtype, but the difference was not statistically significant $(p=0.07)$ (Figure $4 \mathrm{~B})$. Under light-adapted conditions with very bright flashes, to derive cone responses, a cone specific $b$-wave was recorded. Again, the cone-driven b-wave amplitude was decreased in PDGFR $\alpha$ KO mice $(p=0.05)$ (Figure 4C). Under dark-adapted conditions with bright flashes, to derive mixed rod and cone responses, a photoreceptor-mediated a-wave (negative deflection) followed by an inner retina-mediated b-wave (positive deflection) was recorded. The a-wave amplitude was not different $(p=0.12)$, but the b-wave amplitude was significantly reduced in PDGFR $\alpha$ KO mice $(p<0.01)$ (Figure 4D). Decreased b-wave amplitudes in the ERG are a sign of dysfunctional neuronal information processing in the inner retina. The timing of the response, the implicit time, was measured as the time between the flash and the amplitude peak. No differences were found in the ERG implicit time for rod-specific, cone-specific, or mixed b-wave, or in the ERG implicit time-mixed a-wave (Figure 4E-G). In addition, we analyzed the oscillatory potentials (OPs). OPs are high-frequency wavelets on the ascending slope of the b-wave that reflect inner retinal function [31]. The OP amplitudes and the OP implicit times were not significantly different between PDGFR $\alpha$ KO and wildtype mice (Figure $4 \mathrm{H}-\mathrm{J}$ ).
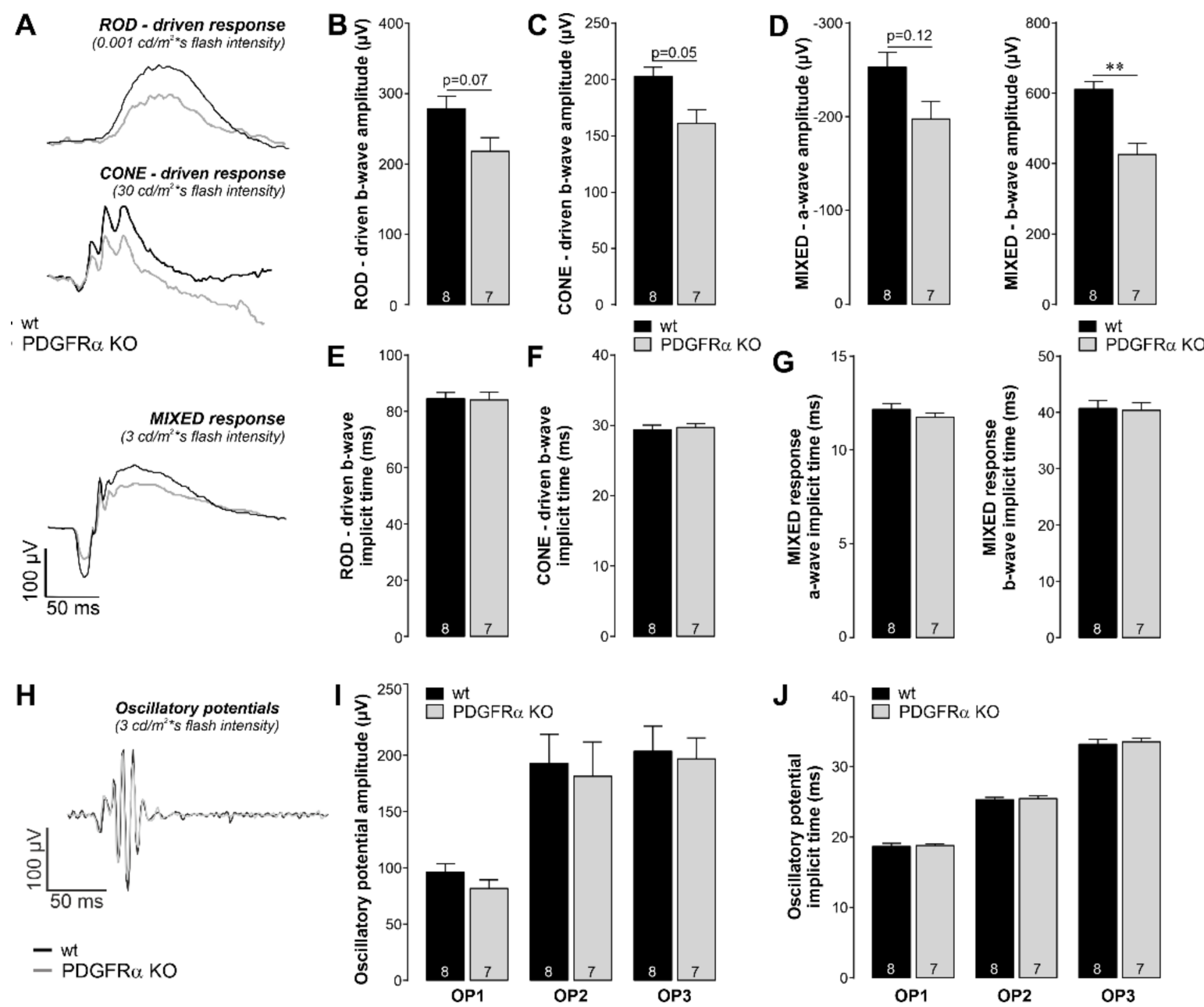

Figure 4. Altered retinal light responses from Müller cell-specific PDGFR $\alpha$-KO mice. (A) Representative electroretinogram (ERG) waveforms for rods (upper), cones (middle), and mixed (lower) responses from wildtype (black) and PDGFR $\alpha$ KO (grey) mice. (B,C) ERG amplitudes for the scotopic rod-specific b-wave (B) and the photopic cone-specific b-wave (C). (D) ERG amplitudes for the mixed rod-cone-specific a-wave and the mixed rod-cone-specific b-wave. (E,F) Implicit times 
for the scotopic rod-specific b-wave (E) and the photopic cone-specific b-wave (F). (G) Implicit times for the mixed rod-cone-specific awave and the mixed rod-cone-specific b-wave. (H) Representative oscillatory potential waveforms for mixed responses. (I) Oscillatory potential amplitudes for the mixed rod-cone-specific response. (J) Oscillatory potential implicit times for the mixed rod-cone-specific response. Amplitudes and implicit times from the first, second, and third positive peaks of the oscillatory potentials were quantified and labeled as OP1, OP2, and OP3, respectively $(\mathbf{I}, \mathbf{J})$. Bars represent mean values \pm SEM from 7 to 8 animals. ${ }^{* *} p<0.01$, Mann-Whitney U-test. For each mouse, the two eyes were averaged.

These findings imply that PDGF signaling in Müller cells has a direct influence on the overall retinal physiology.

\subsection{Vascular Effects of Müller Cell-Specific PDGFR $\alpha$ Knockout in Normal Retina and in a Model} of Choroidal Neovascularization (CNV)

An intact retinal microvasculature is crucial to maintain an adequate blood supply and the functional capacity of the neuronal circuits in the retina. Therefore, we evaluated whether the microvasculature in the PDGFR $\alpha$ KO mouse showed any abnormalities. For this purpose, the endothelium of blood vessels in retinal flatmounts was stained with isolectin B4 (Figure 5A). The superficial vascular plexus was distinguished from the deep vascular plexus (SVP and DVP, respectively) of retinae from wildtype and PDGFR $\alpha$ KO mice in central and peripheral areas of respective specimens. Implementing the angiotool analysis as described by Zudaire et al. [32], we did not detect any major differences between the vasculature from wildtype and PDGFR $\alpha$ KO mice (Figure 5A). Additionally, there was no significant difference regarding vessel density between wildtype and PDGFR $\alpha$ KO retinae when analyzing the SVP or DVP from central or peripheral areas (Figure 5B).
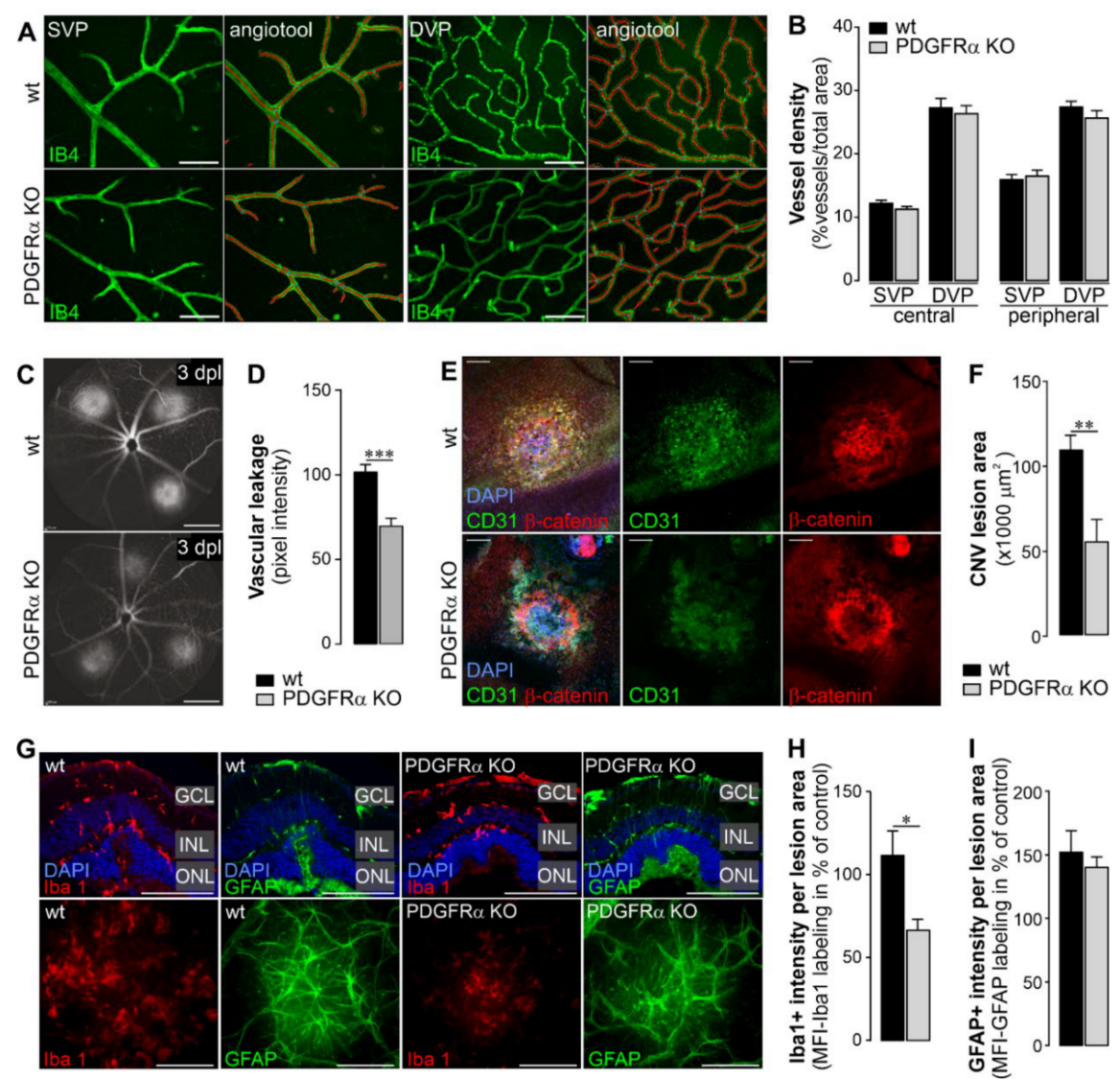

Figure 5. Vascular and inflammatory effects of specific deletion of PDGFR $\alpha$ in Müller cells. (A) Retinae from wildtype (wt) and PDGFR $\alpha$ KO mice were dissected, labeled with isolectin B4 (IB4) to label blood vessels, and flatmounted. Panels show representative retinal images from the superficial vascular plexus (SVP) and the deep vascular plexus (DVP) taken in central areas from the 
flatmount preparation. The resulting image after analysis of vessel density by the angiotool is shown exemplarily. Scale bars, $100 \mu \mathrm{m}$. (B) Quantification of vessel density was performed by analyzing confocal optical slices taken from the SVP and the DVP (composed of the inner deep vascular plexus and the outer deep vascular plexus, respectively) in central and peripheral areas of the retina from wt and PDGFR $\alpha$ KO mice. Bars represent mean \pm SEM from 3-5 animals. (C) Fluorescence angiography performed on eyes at 3 days post laser lesion (dpl) to analyze the functional integrity of the retinal/choroidal blood vessels in wt and PDGFR $\alpha$ KO mice. Scale bars, $200 \mu \mathrm{m}$. (D) Quantification of vascular leakage by analyzing pixel intensities at 3 days after laserinduced retinal damage. Data are shown as mean \pm SEM $(n=6$ eyes). (E) Representative micrographs from laser lesions of retinal eye cups after careful removal of the retina from wt and PDGFR $\alpha$ KO mice scanned via confocal microscopy. Endothelial cells were delineated by CD31-immunoreactivity and RPE cells were detected using $\beta$-catenin-labeling. DAPI was used for nuclear staining. Scale bars, $100 \mu \mathrm{m}$. (F) The area of the lesioned RPE/choroid in flatmount preparations was measured on the basis of CD31 labeling. Data are shown as mean \pm SEM ( $n=4-5)$. (G) Representative micrographs from laser lesions from wt and PDGFR $\alpha$ KO retinae scanned via confocal microscopy. Microglia/macrophages were delineated by Iba1-immunoreactivity and reactive Müller cells as well as astrocytes in the nerve fiber layer were highlighted by staining GFAP. Top, retinal sections through laser lesions. Nuclei were counterstained with DAPI. GCL, ganglion cell layer; INL, inner nuclear layer; ONL, outer nuclear layer. Bottom, maximum projection of z-scans across a laser lesion performed on retinal flatmount preparations. Scale bars, $100 \mu \mathrm{m}$. $(\mathbf{H})$ The labeling intensity for Iba1 (microglia/macrophage marker) was measured across the whole scan field centered over the lesioned retinal area in flatmount preparations. (I) The labeling intensity for GFAP (marker for astrocytes and reactive Müller glia) was measured across the whole scan field centered over the lesioned retinal area in flatmount preparations $(\mathbf{H}, \mathbf{I})$. Bars represent mean \pm SEM ( $n=5)$. (B, D,F,H,I) Mann-Whitney U-test; * $p<0.05,{ }^{* *} p<0.001,{ }^{* * *} p<0.001$.

Given that targeting PDGF has recently been tested as novel therapeutic strategy to treat detrimental neovascularization [8], we continued to analyze whether Müller cellspecific deletion of PDGFR $\alpha$ affected the vascular response to noxious stimuli such as laser lesions of the outer retina, underlying RPE and Bruch's membrane and mimicking aspects of wet age-related macular degeneration [33]. In comparison to their wildtype littermates, Müller cell-specific PDGFR $\alpha$ KO mice presented with a reduced vascular leakage in the $\mathrm{CNV}$ model at three days after laser lesions were in induced (Figure 5C,D). Of note, the area of tissue damage at the level of the RPE/choroid in response to the laser application was also statistically smaller in knockout animals (Figure 5E,F). This suggests that blocking PDGF signaling specifically in Müller cells is sufficient to elicit potent beneficial vascular effects.

Next, we investigated the infiltration of macrophages/microglia and Müller cell gliosis at the lesion site in overlaying retinal tissue. The microglial response in the $\mathrm{KO}$ animals was significantly decreased in comparison to that in wildtype littermates (Figure 5G,H). In contrast, Müller cell gliosis measured on basis of GFAP upregulation did not differ between the two genotypes (Figure 5G,I).

\subsection{Pharmacological Inhibition of PDGF Signaling Had Similar Effects as the Müller Cell-Specific PDGFR $\alpha$ Knockout in the CNV Model}

The findings that neovascular alterations are less pronounced in Müller cell-specific PDGFR $\alpha$ mice (Figure 5) prompted us to ask whether pharmacological inhibition of PDGF signaling has effects comparable to its genetic ablation. Similar to the experiments in the PDGFR $\alpha$ knockout mice, eyes were lasered in three spots and immediately thereafter were injected (i) either with control IgG, (ii) anti-PDGFR $\beta$ antibody (known to effectively block PDGF signaling) alone, or (iii) in combination with an anti-VEGF antibody. The animals were analyzed according to the same protocols used for the Müller cell-specific PDGFR $\alpha$ KO mice. Fluorescence angiography three days after laser lesion demonstrated that anti-PDGFR $\beta$ treatment alone showed similar beneficial effects regarding vascular leakage and lesion size as in combination with anti-VEGF (Figure 6A,B) and as found in 
Müller cell-specific PDGFR $\alpha$ mice (Figure 5C-F). This suggests that the blockade of PDGFR signaling alone (no matter whether it is targeted via PDGFR $\alpha$ or $-\beta$ ) is sufficient to achieve a significantly improved vascular integrity (Figures $5 \mathrm{D}$ and $6 \mathrm{~A}$ ) and smaller lesion size at the level of the RPE/choroid (Figures 5F and 6B) compared to lasered eyes treated with the control IgG or in respective wildtypes. Of note, no clear additive effect of a concomitant anti-VEGF treatment was observed in this experimental setting.

Analogous to the experiments in the Müller cell-specific PDGFR $\alpha$ KO mice, less microglia accumulated in the retina tissue at the lesion site if mice were treated either with anti-PDGFR $\alpha$ alone or in combination with anti-VEGF antibodies (Figure 6C). The effect size was comparable to what we found in PDGFR $\alpha$ KO mice (Figure 5H). Moreover, we found strong upregulation of the Müller cell gliosis marker GFAP in the lesioned area (Figure 6D), but less Müller cells up-regulated GFAP in retinae if treated with anti-PDGFR $\beta$ or if the combinatorial approach was applied (Figure 6D). In sum, the analysis of marker gene expression confirms an expected glial response upon tissue damage, but only the combination of PDGFR $\beta$ and anti-VEGF antibodies seems to significantly dampen Müller gliosis induction.

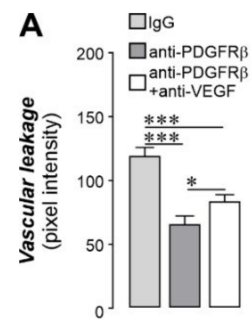

B

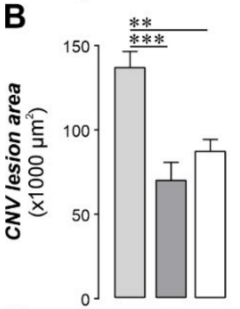

C

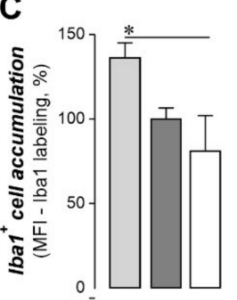

D

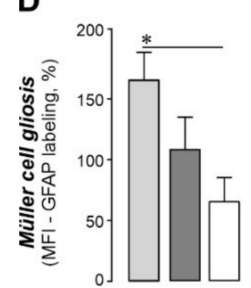

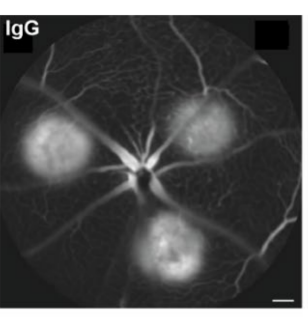
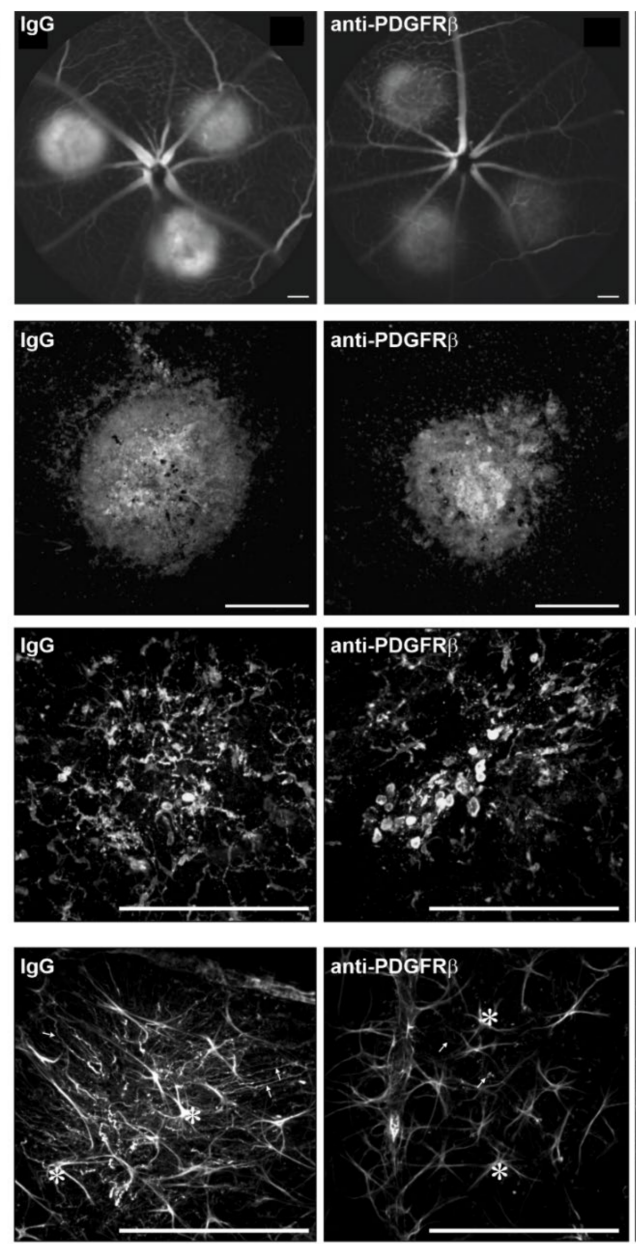

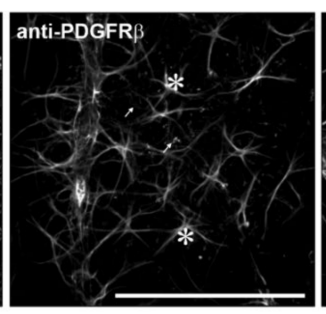

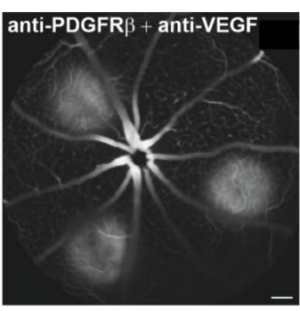
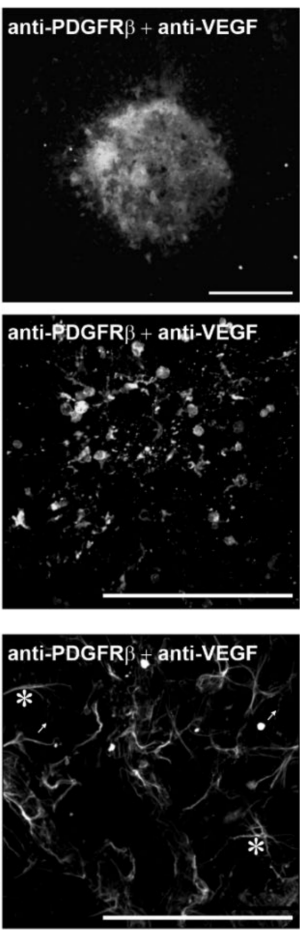

Figure 6. Anti-PDGFR $\beta$ treatment has similar effects on vascular integrity and the glial response pattern as a combined anti-PDGFR $\beta$ /anti-VEGF therapy in a murine model of choroidal neovascularization (CNV). (A) Left, quantification of vascular leakage by analyzing pixel intensities at 3 days after laserinduced retinal damage. The follow antibody concentrations were used: IgG control $(1 \mu \mathrm{g})$, anti-PDGFR $\beta$ $(1 \mu \mathrm{g})$, or anti-PDGFR $\beta+$ anti-VEGF (each $1 \mu \mathrm{g})$. Data are shown as mean \pm SEM $(\mathrm{n}=14-20$ eyes). Right, fluorescence angiography performed on eyes at 3 days after laser lesion to assess data on the functional integrity of the retinal/choroidal blood vessels with or without treatment with anti-PDGFR $\beta$ 
alone or in combination with anti-VEGF antibodies. (B) Left, the area of the lesioned RPE/choroid in flatmount preparations was measured on basis of the CD31 labeling. Data are shown as mean \pm SEM ( $n=6-10)$. Right, representative micrographs from laser lesions from eyes that either received control IgG, anti-PDGFR $\beta$ alone, or in combination with anti-VEGF antibodies scanned via confocal microscopy. Endothelial cells are delineated by CD31 immunoreactivity. (C) Left, the labeling intensity for Iba1 (microglia/macrophage marker) was measured across the whole scan field $(450 \mu \mathrm{m} \times 450 \mu \mathrm{m})$ centered over the lesioned area in retinal flatmount preparations. A maximum intensity projection from a z-stack scanned through whole thickness of that retinal area was used for evaluation. Data are shown as mean \pm SEM ( $n=4$ animals per treatment group). Right, representative maximum intensity projection of $\mathrm{z}$-stacks from Iba1-stained retinal flatmount preparations collected from mice from the respective treatment groups scanned via confocal microscopy. (D) Left, the labeling intensity for GFAP (marker for retinal astrocytes (asterisk) and gliotic Müller cells (arrows)) was measured across the whole scan field $(450 \mu \mathrm{m} \times 450 \mu \mathrm{m})$ centered over the lesioned retinal area in flatmount preparations. A maximum intensity projection from a z-stack scanned through whole thickness of that retinal area was used for evaluation. Data are shown as mean \pm SEM ( $n=4$ animals per treatment group). Right, representative maximum intensity projection of z-stacks from GFAP-stained retinal flatmount preparations collected from mice from the respective treatment groups scanned via confocal microscopy. (A-D) Mann-Whitney U-test, ${ }^{*} p<0.05$, ${ }^{* *} p<0.01,{ }^{* * *} p<0.001$. (A-D) Scale bars, $200 \mu \mathrm{m}$.

\section{Discussion}

PDGF signaling has been shown to be essential for embryonic development of the retina [34] and a contribution to pathological ocular neovascularization is well established [35]. However, in the mature retina the physiological function of PDGF signaling remains largely unexplored. PDGFR $\alpha$ expression is confined to a few cell types in the eye, such as astrocytes and amacrine cells [36]. Others reported its expression in Müller glia in the developing [11] and adult rodent retina [12,37]. Supporting evidence for PDGFR $\alpha$ expression in Müller glia comes from studies using MIO-M1 cells, an immortalized human Müller cell line [38], and rat primary Müller cell cultures [11]. However, to date an unequivocal proof of PDGFR $\alpha$ expression by Müller cells and data about its functional relevance are lacking. Using a novel technique to purify intact Müller cells from adult mouse retinas [26], we confirmed that they indeed express pdgfra at the mRNA and protein level and, importantly, that expression in Müller cells is higher than in any other retinal cell type (Figure 1C). Moreover, we found other components of the PDGF pathway such as pdgfrb and the ligand $p d g f b$ to be expressed at considerable levels by Müller cells (Figure 1C), suggesting a key role of PDGF signaling for Müller cell physiology.

Knockout studies of PDGF family genes have demonstrated that they play an essential role during development and specifically on the establishment of the neurovascular unit. A mutation of PDGFR $\alpha$ in a domain key to mediate downstream signal transduction resulted in defects in the blood and kidney glomerulus formation so that homozygotes died perinatally [39]. In line with that, a null mutation in the gene encoding the PDGF-BB chain led to lethal renal and hematological abnormalities plus cardiovascular defects [40]. Given the perinatal death of the respective KO animals, many primary functions of PDGF signaling remained elusive until evaluated in experiments using conditional gene ablation as in the current study. In the retina, the importance of PDGF-BB has been shown by the ablation of endothelium-derived PDGF-BB, which resulted in reduced retinal pericyte coverage. These mice presented with a vascular phenotype recapitulating features of diabetic retinopathy (venous tortuosity, regressing capillary branches, and microaneurysms) [41]. A similar effect was found in a CNS-specific PDGFR $\alpha$ mutant mouse [42]. These animals exhibited vascular leakage and retinal neurodegeneration, including ganglion cell apoptosis. Finally, it has been described that when PDGF signaling was disrupted in the developing eye by injection of anti-PDGF-A antibodies or the extracellular domain for PDGFR $\alpha$, a strong growth inhibition of the retinal astrocyte network and a concomitantly reduced vascular plexus formation was induced [43]. Despite these reports, we did not find major alterations 
in retinal morphology, vascular architecture, or signs of cell death (Figures 2, S1 and S2) in the newly generated Müller cell-specific PDGFR $\alpha$ KO mouse model. It is likely that the cell type (Müller glia) and time-specific knockout of PDGFR $\alpha$ accounts for the lack of a morphological phenotype. The critical phases of migration and maturation of retinal cells and the establishment of the retinal vascular plexus is largely finished by the end of the fourth postnatal week in mice [44-46] and, thus, weeks before the actual knockout was induced by tamoxifen injection (adult mice, 12-16 weeks of age).

Intense neural activity leads to continuous, local changes of osmotic gradients and ion concentrations. Müller cells are prominently involved in controlling the extracellular ion and fluid homeostasis in the retina and especially of its inner layers (GCL, INL) [47]. Growth factors such as VEGF or heparin-binding epidermal growth factor (HB-EGF), acting via receptor tyrosine kinase receptors such as PDGF, induce a glutamatergic-purinergic signaling cascade key for Müller cell volume regulation and, therefore, also their homeostasis functions [27,48]. In line with that, we found that the capability of PDGFR $\alpha$-deficient Müller cells to counterbalance osmotic stress was severely diminished (Figure 3D). Finding no major morphological differences together with this clear functional phenotype seems counterintuitive. However, this can possibly be explained by the fact that under normal conditions the remaining homeostatic function of Müller cells, e.g., mediated by Kir4.1 potassium channels, showed to be normally expressed in the $\mathrm{KO}$ mice, and this seems to be sufficient to support neuronal survival. Of note, in a recent study we observed a similar phenotype in mice deficient in the ATP receptor P2 $Y_{1}$. As in Müller cell-specific PDGFR $\alpha$ KO mice, Müller cells of $\mathrm{P}_{2} \mathrm{Y}_{1} \mathrm{KO}$ mice were unable to perform efficient cell volume regulation, but no effects on retinal integrity were observed [49].

Having demonstrated Müller cell dysfunction in PDGFR $\alpha$ KO prompted the question of whether visual function might be compromised, given earlier findings that genetically or pharmacological interference with Müller cell homeostasis functions led to changes in the retinal light response. A pharmacological blockade of the glutamate clearance from the synaptic cleft by Müller cells resulted in a reduced b-wave amplitude [50]. Similarly, knockout of the water channel AQP4, also key for Müller cell volume regulation [51], led to alterations of the b-wave in respective mice [52]. In line with this, a recent study on neuromyelitis optica, an autoimmune disease where anti-AQP4 antibodies are formed [53], correlated Müller cell dysfunction with electrophysiological disturbances in affected patients. In sum, these studies point out the importance of Müller glia homeostasis in regulating neuronal function and, thus, the retinal light response. This idea is further supported by a recent study, where the accumulation of $\mathrm{N}$-(3-formyl-3,4-dehydropiperidino)lysine (FDP)-lysine in Müller glial was inhibited using a targeted Müller glia acrolein-scavenging drug to improve glial function in a rat model of diabetic retinopathy [54]. This treatment resulted in a significantly improved disease outcome, including an increased ERG responsiveness. Accordingly, we hypothesize that the dysfunctional Müller cell homeostasis in the PDGFR $\alpha$ KO mice contributes to the observed reduction in retinal light response measured by ERG recordings (Figure 4). Since significant differences were primarily observed for the b-wave together with the understanding that the b-wave reflects the activity of cells of the inner retinal layers, we speculate that especially cells of the inner retinal layers (INL, GCL) closely rely on intact Müller cells to integrate and process signals from photoreceptors normally. This would be in accordance with our earlier study demonstrating that ganglion and amacrine cells are more susceptible to a diminished homeostasis function of Müller cells [49].

Of note, the ERG findings seem to partially contradict results from the initial morphometric analysis where no major differences regarding gross retinal architecture were observed (Figure 2). However, it is well described that even if cells per se are still present, their function can be largely diminished, thus leading to early changes in ERG amplitudes [55].

The importance of functional Müller cells for the integrity of the retinal vascular system was demonstrated by Shen et al [17]. Selective Müller cell ablation led to vascular 
leakage and intraretinal neovascularization. In the absence of any specific exogenous challenge, the retinal microvasculature from Müller cell-specific PDGFR $\alpha$ KO mice showed no anomalies. The vascular density of the different plexus along the central and peripheral retina remained unchanged and we did not detect signs of degeneration of vascular cells, e.g., by evaluation via a TUNEL assay (Figure S2C). Although key for Müller cell volume regulation, this implies that PDGFR $\alpha$ in Müller cells is not essential to maintain mature retinal microvessels-at least not over the times span investigated in the present study. Interestingly, PDGFR $\alpha$ deficiency in Müller cells even turned out to mitigate vascular abnormalities in the CNV model used to test for the tissue response on a pathological stimulus (Figure 5). This model recapitulates aspects of neovascular age-related macular degeneration (AMD), is highly reproducible [56-58] and evaluating leakage of fluorescein dye by angiography is a clinically relevant method to analyze the vasopermeability of CNV lesions $[59,60]$. The reduced vascular hyperpermeability and growth of laser-induced $\mathrm{CNV}$ lesions in Müller cell-specific PDGFR $\alpha$ KO mice are key findings of the present study (Figure 5). These results are in line with a recent study demonstrating that inhibition of PDGF signaling using an aptamer in the same CNV model also reduced the size of the laser lesions [6]. Furthermore, systemic administration of imatinib (targeting PDGFR $\alpha$ and $\beta$ ) improved the outcome in a mouse model of oxygen-induced retinopathy-another model of retinal neovascularization [61].

In addition to the described vascular changes, the CNV model comprises inflammatory components possibly contributing to lesion formation. It has been shown that macrophages/microglia are involved in CNV formation in animal models and in AMD patients [62,63]. Interestingly, we found that the disruption of Müller cell-specific PDGF signaling impacts inflammation during pathological angiogenesis, as the recruitment of microglia and macrophages was significantly diminished (Figure 5G-I). Others achieved similar effects by blocking VEGF receptor 1 and 2 [64]. Two possible pathways why the vascular permeability, the lesion area, and the microglial response upon anti-VEGF treatment were reduced have been discussed: (i) The disruption of VEGF either disturbed an autocrine mechanism regulating the production of pro-inflammatory factors, or (ii) it blocked paracrine intercellular communication, stimulating neighboring cells to generate inflammatory factors. The precise mechanism underlying the beneficial effects observed on vascular hyperpermeability and inflammation in the Müller cell-specific PDGFR $\alpha$ KO mice remains to be identified, but since receptors and ligands are expressed by Müller cells and cells of the neurovascular unit, paracrine and autocrine pathways are likely to be involved.

Next, we compared effects observed in Müller cell-specific PDGFR $\alpha$ KO mice with the pharmacological inhibition of the PDGF axis alone and in combination with anti-VEGF antibodies. Anti-VEGF drugs have revolutionized the management of patients with retinal neovascular diseases [65]. Despite currently being the gold-standard treatment, anti-VEGF therapy is not universally effective [66,67]. There are patients that are unresponsive or become refractory $[68,69]$. In consequence, novel treatment approaches combining antiVEGF therapy with other agents (including PDGF) acting synergistically are subject of (pre-)clinical trials [6,9]. Interestingly, the effectiveness of targeting the PDGF pathway in Müller cells either genetically or by pharmacological blockade (anti-PDGFR $\alpha$ antibodies alone or in combination with anti-VEGF antibodies) to reduce neovascularization and neuroinflammation was highly comparable in the CNV model, but did not show significant synergism as one might would have expected from earlier reports (Figures 5 and 6). There are several factors potentially influencing the synergistic effects of a parallel VEGF and PDGF blockade. Among those the route of application, the assessment time points, and the animal model used should be considered. In comparison with Jo et al. [6], we analyzed the effects at a different time point-namely, at three days post laser lesion instead of 14 days. Our rationale was to avoid the potential spontaneous regression of the vascular lesion that was reported by others [70]. Possibly the inhibitory effect of the combinatorial treatment or the PDGFR $\alpha$ KO on microglial and Müller cell activation holds potential to prevent excessive scar formation, which should be characterized in depth in future studies 
analyzing later time points (e.g., at two and three weeks after laser lesion). This would then also help to approach the question of potential synergistic effects at later time points in more detail.

Finally, it needs to be discussed whether a pharmacological blockade of retinal PDGF signaling does result in similar adverse effects on Müller cell and retinal function, as described for the PDGFR $\alpha$ KO mice. For sure, here the main question is the time span over which the therapy is implemented and the efficiency of the blockade of the PDGF pathway over time. If the therapeutic regimen follows the current scheme of monthly or even less frequent intravitreal antibody injections, it can be assumed that PDGF signaling will not be totally blocked throughout the complete treatment interval. This could, on the one hand, limit the therapeutic effect on neovessels, but on the other be beneficial to maintain a basal Müller cell homeostasis function that is key for normal neuronal function, which we demonstrated here. In the case of gene therapeutic approaches, e.g., expressing the therapeutic antibody via adeno-associated virus (AAV)-based vectors and as currently tested in clinical trials targeting the VEGF pathway ([71,72]; reviewed in [73]), we would speculate that unwarranted side effects on Müller cell homeostatic functions would be more pronounced. This hypothesis is supported be findings from VEGF knockout mice, demonstrating that total absence thereof leads to neurodegeneration [10]. Together with the data from our present study, we consider that these aspects have to be taken into account when determining the safety profile of such new treatment approaches of neovascular diseases permanently blocking retinal VEGF or PDGF signaling pathways.

\section{Materials and Methods}

\subsection{Experimental Animals}

Mice were maintained with ad libitum water and food access in an air-conditioned room on a $12 \mathrm{~h}$ light-dark schedule. Experiments were done in accordance with the ARVO Statement for the Use of Animals in Ophthalmic and Vision Research and with the European Community Council Directive 2010/63/EU. They were approved by the local authorities (55.2-2532.Vet_02_18_47; Bavaria, Germany and 84-02.04.2017.A130; Landesamt für Natur, Umwelt und Verbraucherschutz Nordrhein-Westfalen, Germany). All experimental procedures were performed with adult (2-6-month-old) animals from mixed genders of respective mouse strains. For inducible deletion of PDGFR $\alpha$ in Müller cells, mice carrying floxed alleles (PDGFR $\alpha^{\mathrm{fl} / \mathrm{fl}}$ ) were crossed with Glast-CreER ${ }^{\mathrm{T} 2}$ mice [74]. Mice were bred from heterozygous Glast-CreERT2 and PDGFR $\alpha^{+/ f l}$ parents to obtain Glast-CreERT2; $\operatorname{PDGFR} \alpha^{\mathrm{fl} / \mathrm{fl}}$ homozygotes and Glast-CreERT2; PDGFR $\alpha^{+/+}$littermate wildtype controls, respectively. To revalidate the efficiency and specificity to Müller cells of the Glast-CreER ${ }^{\mathrm{T} 2}$ mice, they were also crossbred with the tdTomato-expressing reporter mouse line Ai3 [24].

\subsection{Recombination Induced by Tamoxifen Administration}

To induce Cre-mediated recombination, tamoxifen was thoroughly dissolved at $42{ }^{\circ} \mathrm{C}$ in ethanol (100 mg/mL; Sigma Aldrich, Schnelldorf, Germany), diluted with corn oil to a final concentration of $10 \mathrm{mg} / \mathrm{mL}$, and finally administered intraperitoneally $(20 \mu \mathrm{g} / \mathrm{g}$ body weight) every day for 3 consecutive days. Mice were analyzed 4 weeks after the final day of tamoxifen administration to ensure clearance of the targeted protein.

\subsection{In Vivo Laser Model for Choroidal Neovascularization (CNV)}

Mice were anesthetized by intraperitoneal injection of a mixture of ketamine/xylazine (100 mg/5 mg per $\mathrm{kg}$ bodyweight), and laser coagulation of the retina was performed using a $532 \mathrm{~nm}$ green laser with a slit-lamp mounted diode laser system (Quantel Medical Vitra, Cournon d'Auvergne, France). The pupil dilation was achieved with $0.5 \%$ tropicamidephenylephrine $2.5 \%$ eye drops before laser treatment. Three laser burns per eye (energy $125 \mathrm{~mW}$, duration $100 \mathrm{~ms}$, spot size $100 \mu \mathrm{m}$ ) were applied around the optic nerve of both eyes with a cover glass as contact lens for fundus fluorescein angiography (FA) and immunohistochemistry (IHC) [75]. For mRNA expression analysis the number of 
laser spots per eye was 20. Rupture of the Bruch's membrane was validated post-laser by examination of retinal structure in vivo using a Spectralis ${ }^{\text {TM }}$ HRA/OCT device (Heidelberg Engineering, Heidelberg, Germany). Lesions with hemorrhage and eye opacities with a pre-existing corneal scar or cataract as well as insufficient disruption of the Bruch's membrane were excluded from analysis.

\subsection{Intravitreal Drug Administration}

The animals were randomly assigned to the experimental groups. The compounds used in this study were injected intravitreally (all diluted in 1x phosphate buffered saline) immediately after inducing CNV: $1 \mu \mathrm{L}$ of either anti-PDGFR $\beta(1 \mu \mathrm{g}, \mathrm{CD} 140 \mathrm{~b}$ (APB5), 16-1402-82 eBioscience; San Diego, CA, USA), anti-VEGF-A (VEGF 164, AF-493-NA, R\&D Systems, Wiesbaden, Germany), and combined anti-PDGFR $\beta$ (each $1 \mu \mathrm{g}$ ) or IgG2a kappa isotype control (1 $\mu \mathrm{g}, 16-4321-81$, eBioscience). To intravitreally administer the aforementioned reagents, a 34-gauge needle was inserted into the vitreal cavity approximately $1.5 \mathrm{~mm}$ below the limbus using a NanoFil Syringe (WorldPrecision Instruments, Sarasota, FL, USA) and the compounds injected bilaterally.

\subsection{Fluorescein Angiography (FA)}

After the induction of anesthesia and pupil dilation of the animals, the vascular leakage was analyzed with the FA mode of the Spectralis ${ }^{\mathrm{TM}}$ HRA/OCT device. For this $100 \mu \mathrm{L}$ of $2.5 \%$ fluorescein (Alcon, Großwallstadt, Germany) diluted in $0.9 \%$ sodium chloride was administered intraperitoneally. Images were acquired $10 \mathrm{~min}$ after fluorescein administration (late phase). Vascular leakage at the $\mathrm{CNV}$ area was analyzed by quantifying the pixel intensity in two regions of interest (ROI) within and one ROI outside each laser spot using the program ImageJ (National Institutes of Health (NIH), Bethesda, MD, USA), and then the background pixel intensity was subtracted from the laser spot values. All 3 laser lesions were averaged to give one experimental value per eye.

\subsection{Immunohistochemical Analysis of Retinal Tissue and Image Analysis}

For immunohistochemical studies, mouse eyes were enucleated and immediately fixed in $4 \%$ paraformaldehyde (Carl Roth, Karlsruhe, Germany) in $\mathrm{pH} 7.4$ for $2 \mathrm{~h}$ at room temperature. The anterior segments were carefully dissected out under a biopsy microscope, and the neurosensory retina and the RPE-choroid-sclera were detached and isolated from the optic nerve head. Four to six radial cuts in the remaining retina and RPE-choroid-sclera were made in the direction of the equator. The dissected retinal and RPEchoroid-sclera flatmounts were incubated in the primary antibodies diluted in blocking solution (3\% dimethyl sulfoxide, $0.3 \%$ Triton $\mathrm{X}-100$, and $5 \%$ of an appropriate serum diluted in PBS) overnight at $4{ }^{\circ} \mathrm{C}$ (Table S1). The flatmounts were then incubated in a 1:1000 dilution of their respective fluorescent secondary antibodies overnight at $4{ }^{\circ} \mathrm{C}$, followed by washing with PBS.

Another group of mice was euthanized and their eye cups were dissected and fixed in $4 \%$ paraformaldehyde solution for $2 \mathrm{~h}$ and cryoprotected in a solution of $30 \%$ sucrose overnight. Then they were embedded in cryomatrix ${ }^{\mathrm{TM}}$ (Thermo Fisher Scientific, Schwerte, Germany) and sectioned into $10 \mu \mathrm{m}$-thick slices and stained using a similar protocol as for retinal flatmounts. Experiments in which primary antibodies were omitted served as negative controls.

After the final wash with 1X PBS, the retina, RPE-choroid flatmounts, and cryosections were mounted and embedded using aqua-poly/mount (18606-20; Polysciences Europe, Hirschberg an der Bergstrasse, Germany). Samples were scanned using confocal microscopy (custom-made VisiScope CSU-X1 confocal system equipped with a highresolution sCMOS camera; Visitron Systems, Puchheim, Germany). The apoptosis of retinal cells was assayed using a terminal deoxynucleotidyl transferase dUTP Nick End Labeling (TUNEL) assay according to the manufacture's specifications (Roche Molecular Biochemicals, Mannheim, Germany). Using ImageJ [76], we quantified the cell nuclei in 
the different retinal layers and calretinin-positive cells. Areas of the central retina that were $150 \mu \mathrm{m}$ wide and close to the optic nerve head (to avoid eccentricity-dependent effects) were chosen for the analysis (optical slice thickness, $1.5 \mu \mathrm{m}$ ). For histological analysis, at least 3 animals per genotype were investigated, from which representative micrographs were chosen for presentation in respective figures.

\subsection{Retinal Vasculature Labeling and Quantification}

Retinal flatmounts were prepared and the blood vessels were stained using fluoresceinconjugated isolectin B4 (IB4) (Table S1). Immunostaining with IB4 and DAPI was performed for two days at $4{ }^{\circ} \mathrm{C}$. Following incubation with the antibodies, retinae were washed 3 times for 5 min each in phosphate buffer solution (PBS) and were embedded using aqua-poly/mount (18606-20; Polysciences Europe). For analysis, multiplane z-series were collected from fields of views of the vascular network from wildtype and $\mathrm{KO}$ mice by using $25 \times$ objective lens (VisiScope CSU-X1 confocal system; Visitron Systems). The series included the vitreal surface to the outer plexiform layer (OPL), and we captured at least 4 fluorescent images/retina/central and peripheral areas. Next, we performed a z-stack projection, dividing the z-series in two sets: the superficial vascular plexus (SVP) and the deep vascular plexus (DVP). The retinal vessel density was quantified using the angiotool software [32].

\subsection{CNV Lesion Area Quantification}

To analyze the lesion area, the RPE-choroid-sclera complex was stained using two different markers to delimitate the laser injury site-the endothelial cell marker CD31 and the RPE marker $\beta$-catenin (evaluation of RPE cell disruption). Images were obtained using a 10X objective lens focusing on the laser spot by confocal microscopy (VisiScope CSU-X1 confocal system, Visitron System). Image (NIH) was used to measure the lesion size in a masked fashion. Lesions were excluded when there was obvious damage due to tissue processing. The mean lesion size obtained from all 3 lesions per eye was plotted as one experimental value per animal and was subjected to further statistical analysis.

\subsection{Müller Cell Reactivity and Macrophage/Microglia Accumulation Evaluation}

Müller cell reactivity and macrophage/microglia recruitment were evaluated by measuring the intensity of the GFAP+ and Iba+ signal respectively in the retinal flatmounts. For that purpose, z-stacks reaching 100-120 $\mu \mathrm{m}$ into the retinal tissue (starting at the nerve fiber layer) were obtained using a $25 \times$ objective lens of the confocal microscope (previously described) at the site of the lesion. The mean fluorescence intensity was analyzed by ImageJ software (NIH). The final values are expressed as percentages, after background signal normalization to that detected in non-lesioned regions.

\subsection{Müller Cell Soma Swelling and Volume Regulation}

Freshly isolated retinal slices (1 $\mathrm{mm}$ thickness) were prepared and placed with the photoreceptor side onto membrane filters $(0.45 \mu \mathrm{m}$, diameter $50 \mathrm{~mm}$; GE Healthcare Life Sciences, Freiburg, Germany). Volume changes of Müller cell somata evoked under isotonic conditions and after hypoosmotic challenge ( $60 \%$ of control osmolarity) were measured in the inner nuclear layer of retinal slices as previously described [77]. The retinal slices from wildtype and $\mathrm{KO}$ mice were placed in a perfusion chamber (custom made) and loaded with the vital dye Mitotracker Orange $(10 \mu \mathrm{M}$, excitation $543 \mathrm{~nm}$, emission $560 \mathrm{~nm}$-long pass filter; Thermo Fisher Scientific). The Mitotracker Orange dye selectively stained Müller glia [78], and the stock solution was prepared in DMSO and diluted 1:1000 in PBS. The slices were examined during exposure to a hypotonic solution for $4 \mathrm{~min}$ with or without test agents using confocal microscopy (custom-made VisiScope CSU-X1 confocal system equipped with a high-resolution sCMOS camera; Visitron Systems). The cell soma area of labeled Müller cells was cross-sectionally measured (ImageJ). The blocking agent was pre-incubated for 10 min in extracellular solution; AC710 (PDGFR family inhibitor; Tocris 
Bioscience, Bristol, UK) 100 nM. PDGF-BB, a PDGF receptor $\alpha / \beta$ agonist (R\&D Systems), was applied simultaneously with the hypotonic solution.

\subsection{Magnetic-Activated Cell Sorting (MACS) of Retinal Cell Types}

Müller cells were enriched from isolated retinae by magnetic-activated cell sorting (MACS) as described previously [25]. Briefly, the isolated retinae were digested in papain $(0.2 \mathrm{mg} / \mathrm{mL})$ for $30 \mathrm{~min}$ at $37^{\circ} \mathrm{C}$, in $\mathrm{Ca}^{2+}$ - and $\mathrm{Mg}^{2+}$-free extracellular solution. Afterwards, the retinae were shortly incubated with DNaseI $(200 \mathrm{U} / \mathrm{mL}$, Roche Molecular Biochemicals) and triturated. After centrifugation, the retinal tissue was resuspended and subsequently incubated with CD11b and CD31 microbeads according to the standard manufacturer's protocol (Miltenyi Biotec, Bergisch Gladbach, Germany) to obtain microglial and vascular cell-enriched fractions; the respective binding cells were depleted from the retinal suspension using large cell columns (Miltenyi Biotec) prior to Müller cell enrichment. After washing, Müller cells were purified by incubating the retinal suspension in extracellular solution containing biotinylated anti-CD29 (Miltenyi Biotec) for 15 min at $4{ }^{\circ} \mathrm{C}$. The cell population in the flow through depleted CD11b+, CD31+, and CD29+ cells was considered the neuronal fraction [26,79]). Nonetheless, a minor contamination with other cell types could not be ruled out. To assess the purity of the CD29+ Müller cell fraction, the cell suspension was checked via immunostaining using the Müller glia marker glutamine synthetase together with a DAPI counterstain to quantify total cell numbers. As described previously [25], Müller cell purity was more than $80 \%$, with photoreceptors being the main contaminating cell type. Freshly isolated CD29+ Müller cells and the respective CD29neuronal fraction from PDGFR $\alpha \mathrm{KO}$ and wildtype mice were used to validate the Müller cell-specific deletion of PDGFR $\alpha$ by immunofluorescence using the previously described protocol for cryosection staining.

\subsection{Gene Expression Analyses}

Total RNA was isolated after the immunoseparation of retinal cell subpopulations using the RNeasy Micro Kit (Purelink RNA Micro Scale kit, Thermo Fisher Scientific) with the supplied manufacturer's instructions. To remove genomic DNA contamination a DNase digestion step was added (Roche Molecular Biochemicals). cDNA was synthetized with the RevertAid H Minus First-strand cDNA Synthesis kit (Fermentas by Thermo Fisher Scientific, Schwerte, Germany) using 10-50 ng of total RNA. To evaluate candidate gene expression levels, primers were designed using the Universal ProbeLibrary Assay Design Center (Roche Molecular Biochemicals). Quantitative real-time PCR (qPCR) was performed using cDNA from respective enriched cell populations with the TaqMan hPSC Scorecard ${ }^{\mathrm{TM}}$ Panel (384 well, ViiA7, Life Technologies, Darmstadt, Germany) according to the company's guidelines. Expression levels of respective complement genes (for primer sequences see Table 1) were normalized to the expression of isocitrate dehydrogenase 3 (NAD+) beta (idh3b) that we validated in a recent studied to fulfill the criteria of a good housekeeping gene across retinal cell populations [80].

Table 1. Primer and TaqMan probe combinations for detection of the respective mRNA via qPCR.

\begin{tabular}{|c|c|c|c|c|}
\hline Gene ID & $\begin{array}{c}\text { Primer Sequences: } \\
\text { Forward }\end{array}$ & $\begin{array}{c}\text { Primer Sequences: } \\
\text { Reverse }\end{array}$ & $\begin{array}{c}\text { TaqMan }^{\circledR} \text { Probe from } \\
\text { Roche }\end{array}$ & Accession Number \\
\hline idh3b & $5^{\prime}$ gctgcggcatctcaatct $3^{\prime}$ & $5^{\prime}$ ccatgtctcgagtccgtacc $3^{\prime}$ & \# 67 & NM_130884.4 \\
\hline aif1 & $5^{\prime}$ atctgccgtccaaacttga $3^{\prime}$ & $5^{\prime}$ ctaggtgggtcttgggaacc $3^{\prime}$ & \# 67 & NM_001361501.1 \\
\hline glul & $5^{\prime}$ gcccaagtgtgtggaagag $3^{\prime}$ & $5^{\prime}$ aaggggtctcgaaacatgg $3^{\prime}$ & \# 58 & NM_008131.4 \\
\hline nrl & $5^{\prime}$ tgcctttctggttctgacagt $3^{\prime}$ & $5^{\prime}$ gaaagccattctgggactga $3^{\prime}$ & \# 53 & NM_008736.3 \\
\hline pecam1 & $5^{\prime}$ gctggtgctctatgcaagc $3^{\prime}$ & $5^{\prime}$ atggatgctgttgatggtga $3^{\prime}$ & \# 64 & NM_008816.3 \\
\hline pdgfra & $5^{\prime}$ cagacattgaccctgttcca $3^{\prime}$ & $5^{\prime}$ tctcttccgaagtctgtgagc $3^{\prime}$ & \# 69 & NM_001083316.2 \\
\hline pdgfrb & $5^{\prime}$ tcaagctgcaggtcaatgtc $3^{\prime}$ & $5^{\prime}$ ccattggcagggtgactc $3^{\prime}$ & \# 67 & NM_001146268.1 \\
\hline pdgfb & $5^{\prime}$ cggcctgtgactagaagtcc $3^{\prime}$ & $5^{\prime}$ gagcttgaggcgtcttgg $3^{\prime}$ & \# 32 & NM_011057.4 \\
\hline
\end{tabular}




\subsection{Electroretinogram Recording}

Electroretinogram (ERG) recordings were performed 4 weeks after tamoxifen injection and compared to age-matched wildtype littermates. The mice were dark adapted overnight, anesthetized by intraperitoneal injection, and their pupils were fully dilated with $1 \%$ tropicamide and $10 \%$ phenylephrine. Recordings were carried out using an Espion ERG Diagnosys System (Dyagnosys LLL, Littleton, MA, USA) under dim red light illumination. During the recording and recovering, body temperature was maintained at $37^{\circ} \mathrm{C}$ using a heating pad. Electrodes were placed on the cornea and ERG responses were simultaneously recorded from both eyes. Scotopic rod and mixed rod-cone responses were measured using light pulses of 0.001 and $3 \mathrm{~cd} \times \mathrm{s} / \mathrm{m}^{2}$ (white 65,000 K), respectively. After $10 \mathrm{~min}$ of light adaptation in the Ganzfeld dome, photopic responses were recorded. Using light pulses of $30 \mathrm{~cd} \times \mathrm{s} / \mathrm{m}^{2}$ (xenon), the a-wave amplitude was measured from baseline to the trough of the a-wave, and the b-wave amplitude from the trough of the a-wave to the peak of the b-wave. The a- and b-wave implicit times were quantified from the stimulus onset to the peak of the respective wave form. Additionally, the oscillatory potentials (OP) of the ERG were isolated and the first, second, and third positive peak amplitudes and implicit times were then plotted as OP1, OP2, and OP3, respectively.

\subsection{Statistical Analysis}

The data were analyzed using Prism (Graphpad Prism Software 7.1, San Diego, CA, USA) and reported as mean values \pm standard error (SEM). In order to comply with the three Rs principle of animal welfare, the majority of the experiments in the current study came from 4 biological replicates unless stated otherwise. Therefore, we analyzed the significance levels using the non-parametric, two-tailed Mann-Whitney U-test, given that with this number of cases a normal Gaussian distribution could not be assumed. In each figure legend the specific n-values and significance levels are shown.

\section{Conclusions}

In summary, our data not only provide a first insight into the contribution of glial PDGF signaling to normal retinal function in general and for the physiology of Müller cells specifically, but we could also confirm that components of the PDGF pathway might serve as a target to block pathological ocular angiogenesis. However, our findings may also explain why recent clinical trials blocking PDGF signaling in conjunction with that of VEGF in neovascular retinal disease did not prove to be superior to anti-VEGF mono-therapy. Given that both VEGF and PDGF stimulate important homeostasis functions in Müller cells, too-efficient shutdown of these two pathways, specifically in case of the combinatorial treatment approach, may accelerate negative unwarranted side effects on the ion and fluid retinal homeostasis, interfering with the actual treatment goals, as seen in the failed Fovista phase III clinical trials (https: / clinicaltrials.gov / identifiers: NCT01944839, NCT01940900, NCT01940887; [81]).

Supplementary Materials: The following are available online at https://www.mdpi.com/1422 $-0067 / 22 / 3 / 1174 / s 1$, Figure S1: Evaluation of PDGFR $\alpha$ expression in retinal sections of Müller cell-specific PDGFR $\alpha$ KO mice, Figure S2: Immunoreactivity of additional cell markers in Müller cell-specific PDGFR $\alpha$ retinae, Table S1: Information on primary and secondary antibodies.

Author Contributions: Data collection: N.D.-L., A.W., S.K., A.M.P., J.B., and X.G.; quantitative analysis and statistics: N.D.-L., A.W., and S.K.; data interpretation: N.D.-L., S.K., T.L., and A.G.; literature search: N.D.-L. and A.G.; manuscript preparation: N.D.-L., A.W., S.K., A.M.P., X.G., T.L., and A.G.; conception and design: N.D.-L., T.L., and A.G. All authors have read and agreed to the published version of the manuscript.

Funding: This work was funded by the PRO RETINA-Stiftung and the Bayer GOAP Research Award to AG and by the Ministry of Science, Research and Technology of Mexico City Government (SECITI) 00312/2017 to N.D.-L. 
Institutional Review Board Statement: Experiments were done in accordance with the ARVO Statement for the Use of Animals in Ophthalmic and Vision Research and with the European Com-munity Council Directive 2010/63/EU. They were approved by the local authorities (55.22532.Vet_02_18_47; Bavaria, Germany and 84-02.04.2017.A130; Landesamt für Natur, Umwelt und Verbraucherschutz Nordrhein-Westfalen, Germany).

Informed Consent Statement: Not applicable.

Data Availability Statement: The data presented in this study are available on request from the corresponding author.

Acknowledgments: Thanks to Dirkje Felder and Gabriela Jäger for excellent technical assistance. We thank Frank W. Prieger for providing the Glast-CreERT2 mouse strain.

Conflicts of Interest: We have no conflict of interest to declare.

$\begin{array}{ll}\text { Abbreviations } \\ \text { AQP4 } & \begin{array}{l}\text { aquaporin } 4 \\ \text { central nervous system } \\ \text { CNS }\end{array} \\ \text { CNV } & \begin{array}{l}\text { choroidal neovascularization } \\ \text { electroretinogram }\end{array} \\ \text { ERG } & \text { ganglion cell layer } \\ \text { GCL } & \text { inner plexiform layer } \\ \text { IPL } & \text { inner nuclear layer } \\ \text { INL } & \text { outer plexiform layer } \\ \text { OPL } & \text { outer nuclear layer } \\ \text { ONL } & \text { platelet-derived growth factor } \\ \text { PDGF } & \text { platelet-derived growth factor receptor } \\ \text { PDGFR } & \text { Müller cell-specific platelet-derived growth factor receptor alpha knockout } \\ \text { PDGFR } \alpha \text { KO } & \text { retinal pigment epithelium } \\ \text { RPE } & \text { terminal deoxynucleotidyl transferase dUTP nick end labeling } \\ \text { TUNEL } & \text { vascular endothelial growth factor } \\ \text { VEGF } & \text { wildtype } \\ \text { wt } & \end{array}$

\section{References}

1. Hammes, H.P.; Lin, J.; Renner, O.; Shani, M.; Lundqvist, A.; Betsholtz, C.; Brownlee, M.; Deutsch, U. Pericytes and the pathogenesis of diabetic retinopathy. Diabetes 2002, 51,3107-3112. [CrossRef] [PubMed]

2. Joussen, A.M. Molecular pathogenesis of ocular vascular disease-Anti-angiogenesis as a therapeutic concept. Dtsch. Med. Wochenschr. 2007, 132, 1268-1272. [CrossRef] [PubMed]

3. Ejaz, S.; Chekarova, I.; Ejaz, A.; Sohail, A.; Lim, C.W. Importance of pericytes and mechanisms of pericyte loss during diabetes retinopathy. Diabetes Obes. Metab. 2008, 10, 53-63. [CrossRef] [PubMed]

4. Klaassen, I.; Van Noorden, C.J.; Schlingemann, R.O. Molecular basis of the inner blood-retinal barrier and its breakdown in diabetic macular edema and other pathological conditions. Prog. Retin. Eye Res. 2013, 34, 19-48. [CrossRef]

5. Kim, L.A.; D'Amore, P.A. A brief history of anti-VEGF for the treatment of ocular angiogenesis. Am. J. Pathol. 2012, 181, 376-379. [CrossRef]

6. Jo, N.; Mailhos, C.; Ju, M.; Cheung, E.; Bradley, J.; Nishijima, K.; Robinson, G.S.; Adamis, A.P.; Shima, D.T. Inhibition of platelet-derived growth factor B signaling enhances the efficacy of anti-vascular endothelial growth factor therapy in multiple models of ocular neovascularization. Am. J. Pathol. 2006, 168, 2036-2053. [CrossRef]

7. Spaide, R.F. Rationale for combination therapy in age-related macular degeneration. Retina 2009, 29, S5-S7. [CrossRef]

8. Jaffe, G.J.; Ciulla, T.A.; Ciardella, A.P.; Devin, F.; Dugel, P.U.; Eandi, C.M.; Masonson, H.; Mones, J.; Pearlman, J.A.; Quaranta-El Maftouhi, M.; et al. Dual Antagonism of PDGF and VEGF in Neovascular Age-Related Macular Degeneration: A Phase IIb, Multicenter, Randomized Controlled Trial. Ophthalmology 2017, 124, 224-234. [CrossRef]

9. Dong, A.; Seidel, C.; Snell, D.; Ekawardhani, S.; Ahlskog, J.K.; Baumann, M.; Shen, J.; Iwase, T.; Tian, J.; Stevens, R.; et al. Antagonism of PDGF-BB suppresses subretinal neovascularization and enhances the effects of blocking VEGF-A. Angiogenesis 2014, 17, 553-562. [CrossRef]

10. Saint-Geniez, M.; Maharaj, A.S.; Walshe, T.E.; Tucker, B.A.; Sekiyama, E.; Kurihara, T.; Darland, D.C.; Young, M.J.; D'Amore, P.A. Endogenous VEGF is required for visual function: Evidence for a survival role on muller cells and photoreceptors. PLoS ONE 2008, 3, e3554. [CrossRef] 
11. Mudhar, H.S.; Pollock, R.A.; Wang, C.; Stiles, C.D.; Richardson, W.D. PDGF and its receptors in the developing rodent retina and optic nerve. Development 1993, 118, 539-552. [PubMed]

12. Cox, O.T.; Simpson, D.A.; Stitt, A.W.; Gardiner, T.A. Sources of PDGF expression in murine retina and the effect of short-term diabetes. Mol. Vis. 2003, 9, 665-672. [PubMed]

13. Biswas, S.K.; Zhao, Y.; Nagalingam, A.; Gardner, T.W.; Sandirasegarane, L. PDGF- and insulin/IGF-1-specific distinct modes of class IA PI 3-kinase activation in normal rat retinas and RGC-5 retinal ganglion cells. Investig. Ophthalmol Vis. Sci. 2008, 49, 3687-3698. [CrossRef] [PubMed]

14. Bringmann, A.; Pannicke, T.; Grosche, J.; Francke, M.; Wiedemann, P.; Skatchkov, S.N.; Osborne, N.N.; Reichenbach, A. Muller cells in the healthy and diseased retina. Prog. Retin Eye Res. 2006, 25, 397-424. [CrossRef]

15. Tout, S.; Chan-Ling, T.; Hollander, H.; Stone, J. The role of Muller cells in the formation of the blood-retinal barrier. Neuroscience 1993, 55, 291-301. [CrossRef]

16. Ikuno, Y.; Hibino, S.; Bando, H.; Kawasaki, Y.; Nakamura, T.; Tano, Y. Retinal glial cells stimulate microvascular pericyte proliferation via fibroblast growth factor and platelet-derived growth factor in vitro. Jpn. J. Ophthalmol. 2002, 46, 413-418. [CrossRef]

17. Shen, W.; Fruttiger, M.; Zhu, L.; Chung, S.H.; Barnett, N.L.; Kirk, J.K.; Lee, S.; Coorey, N.J.; Killingsworth, M.; Sherman, L.S.; et al. Conditional Mullercell ablation causes independent neuronal and vascular pathologies in a novel transgenic model. J. Neurosci. 2012, 32, 15715-15727. [CrossRef]

18. Powner, M.B.; Gillies, M.C.; Tretiach, M.; Scott, A.; Guymer, R.H.; Hageman, G.S.; Fruttiger, M. Perifoveal muller cell depletion in a case of macular telangiectasia type 2. Ophthalmology 2010, 117, 2407-2416. [CrossRef]

19. Powner, M.B.; Gillies, M.C.; Zhu, M.; Vevis, K.; Hunyor, A.P.; Fruttiger, M. Loss of Muller's cells and photoreceptors in macular telangiectasia type 2. Ophthalmology 2013, 120, 2344-2352. [CrossRef]

20. Lindblom, P.; Gerhardt, H.; Liebner, S.; Abramsson, A.; Enge, M.; Hellstrom, M.; Backstrom, G.; Fredriksson, S.; Landegren, U.; Nystrom, H.C.; et al. Endothelial PDGF-B retention is required for proper investment of pericytes in the microvessel wall. Genes Dev. 2003, 17, 1835-1840. [CrossRef]

21. Seo, M.S.; Okamoto, N.; Vinores, M.A.; Vinores, S.A.; Hackett, S.F.; Yamada, H.; Yamada, E.; Derevjanik, N.L.; LaRochelle, W.; Zack, D.J.; et al. Photoreceptor-specific expression of platelet-derived growth factor-B results in traction retinal detachment. Am. J. Pathol. 2000, 157, 995-1005. [CrossRef]

22. Vinores, S.A.; Seo, M.S.; Derevjanik, N.L.; Campochiaro, P.A. Photoreceptor-specific overexpression of platelet-derived growth factor induces proliferation of endothelial cells, pericytes, and glial cells and aberrant vascular development: An ultrastructural and immunocytochemical study. Brain Res. Dev. Brain Res. 2003, 140, 169-183. [CrossRef]

23. Edqvist, P.H.; Niklasson, M.; Vidal-Sanz, M.; Hallbook, F.; Forsberg-Nilsson, K. Platelet-derived growth factor over-expression in retinal progenitors results in abnormal retinal vessel formation. PLoS ONE 2012, 7, e42488. [CrossRef]

24. Madisen, L.; Zwingman, T.A.; Sunkin, S.M.; Oh, S.W.; Zariwala, H.A.; Gu, H.; Ng, L.L.; Palmiter, R.D.; Hawrylycz, M.J.; Jones, A.R.; et al. A robust and high-throughput Cre reporting and characterization system for the whole mouse brain. Nat. Neurosci. 2010, 13, 133-140. [CrossRef] [PubMed]

25. Grosche, A.; Hauser, A.; Lepper, M.F.; Mayo, R.; von Toerne, C.; Merl-Pham, J.; Hauck, S.M. The Proteome of Native Adult Muller Glial Cells from Murine Retina. Mol. Cell Proteom. 2016, 15, 462-480. [CrossRef] [PubMed]

26. Mages, K.; Grassmann, F.; Jagle, H.; Rupprecht, R.; Weber, B.H.F.; Hauck, S.M.; Grosche, A. The agonistic TSPO ligand XBD173 attenuates the glial response thereby protecting inner retinal neurons in a murine model of retinal ischemia. J. Neuroinflammation 2019, 16, 43. [CrossRef] [PubMed]

27. Wurm, A.; Pannicke, T.; Wiedemann, P.; Reichenbach, A.; Bringmann, A. Glial cell-derived glutamate mediates autocrine cell volume regulation in the retina: Activation by VEGF. J. Neurochem. 2008, 104, 386-399. [CrossRef]

28. Bringmann, A.; Faude, F.; Reichenbach, A. Mammalian retinal glial (Muller) cells express large-conductance Ca( $\left.{ }^{2+}\right)$-activated $\mathrm{K}+$ channels that are modulated by $\mathrm{Mg}^{2+}$ and $\mathrm{pH}$ and activated by protein kinase A. Glia 1997, 19, 311-323. [CrossRef]

29. Kofuji, P.; Biedermann, B.; Siddharthan, V.; Raap, M.; Iandiev, I.; Milenkovic, I.; Thomzig, A.; Veh, R.W.; Bringmann, A.; Reichenbach, A. Kir potassium channel subunit expression in retinal glial cells: Implications for spatial potassium buffering. Glia 2002, 39, 292-303. [CrossRef]

30. Nagelhus, E.A.; Horio, Y.; Inanobe, A.; Fujita, A.; Haug, F.M.; Nielsen, S.; Kurachi, Y.; Ottersen, O.P. Immunogold evidence suggests that coupling of $\mathrm{K}+$ siphoning and water transport in rat retinal Muller cells is mediated by a coenrichment of Kir4.1 and AQP4 in specific membrane domains. Glia 1999, 26, 47-54. [CrossRef]

31. Weymouth, A.E.; Vingrys, A.J. Rodent electroretinography: Methods for extraction and interpretation of rod and cone responses. Prog. Retin. Eye Res. 2008, 27, 1-44. [CrossRef] [PubMed]

32. Zudaire, E.; Gambardella, L.; Kurcz, C.; Vermeren, S. A computational tool for quantitative analysis of vascular networks. PLoS ONE 2011, 6, e27385. [CrossRef] [PubMed]

33. Balser, C.; Wolf, A.; Herb, M.; Langmann, T. Co-inhibition of PGF and VEGF blocks their expression in mononuclear phagocytes and limits neovascularization and leakage in the murine retina. J. Neuroinflammation 2019, 16, 26. [CrossRef] [PubMed]

34. Andrae, J.; Gallini, R.; Betsholtz, C. Role of platelet-derived growth factors in physiology and medicine. Genes Dev. 2008, 22, 1276-1312. [CrossRef] 
35. Sadiq, M.A.; Hanout, M.; Sarwar, S.; Hassan, M.; Agarwal, A.; Sepah, Y.J.; Do, D.V.; Nguyen, Q.D. Platelet-Derived Growth Factor Inhibitors: A Potential Therapeutic Approach for Ocular Neovascularization. Dev. Ophthalmol. 2016, 55, 310-316. [CrossRef]

36. Takahama, S.; Adetunji, M.O.; Zhao, T.; Chen, S.; Li, W.; Tomarev, S.I. Retinal Astrocytes and GABAergic Wide-Field Amacrine Cells Express PDGFRalpha: Connection to Retinal Ganglion Cell Neuroprotection by PDGF-AA. Investig. Ophthalmol. Vis. Sci. 2017, 58, 4703-4711. [CrossRef]

37. Kanamoto, T.; Rimayanti, U.; Okumuchi, H.; Kiuchi, Y. Platelet-Derived Growth Factor Receptor Alpha Is Associated with Oxidative Stress-Induced Retinal Cell Death. Curr. Eye Res. 2011, 36, 336-340. [CrossRef]

38. Velez, G.; Weingarden, A.R.; Tucker, B.A.; Lei, H.; Kazlauskas, A.; Young, M.J. Retinal Pigment Epithelium and Müller Progenitor Cell Interaction Increase Müller Progenitor Cell Expression of PDGFR. Stem Cells Int. 2012, 2012, 106486. [CrossRef]

39. Soriano, P. Abnormal kidney development and hematological disorders in PDGF beta-receptor mutant mice. Genes Dev. 1994, 8, 1888-1896. [CrossRef]

40. Leveen, P.; Pekny, M.; Gebre-Medhin, S.; Swolin, B.; Larsson, E.; Betsholtz, C. Mice deficient for PDGF B show renal, cardiovascular, and hematological abnormalities. Genes Dev. 1994, 8, 1875-1887. [CrossRef]

41. Enge, M.; Bjarnegard, M.; Gerhardt, H.; Gustafsson, E.; Kalen, M.; Asker, N.; Hammes, H.P.; Shani, M.; Fassler, R.; Betsholtz, C. Endothelium-specific platelet-derived growth factor-B ablation mimics diabetic retinopathy. EMBO J. 2002, 21, 4307-4316. [CrossRef] [PubMed]

42. Jadeja, S.; Mort, R.L.; Keighren, M.; Hart, A.W.; Joynson, R.; Wells, S.; Potter, P.K.; Jackson, I.J. A CNS-specific hypomorphic Pdgfr-beta mutant model of diabetic retinopathy. Investig. Ophthalmol. Vis. Sci. 2013, 54, 3569-3578. [CrossRef] [PubMed]

43. Fruttiger, M.; Calver, A.R.; Kruger, W.H.; Mudhar, H.S.; Michalovich, D.; Takakura, N.; Nishikawa, S.; Richardson, W.D. PDGF mediates a neuron-astrocyte interaction in the developing retina. Neuron 1996, 17, 1117-1131. [CrossRef]

44. Sun, Y.; Smith, L.E.H. Retinal Vasculature in Development and Diseases. Annu. Rev. Vis. Sci. 2018, 4, 101-122. [CrossRef]

45. Zhang, X.; Serb, J.M.; Greenlee, M.H. Mouse retinal development: A dark horse model for systems biology research. Bioinform. Biol. Insights 2011, 5, 99-113. [CrossRef]

46. Amini, R.; Rocha-Martins, M.; Norden, C. Neuronal Migration and Lamination in the Vertebrate Retina. Front. Neurosci. 2017, 11, 742. [CrossRef]

47. Reichenbach, A.; Bringmann, A. New functions of Muller cells. Glia 2013, 61, 651-678. [CrossRef]

48. Weuste, M.; Wurm, A.; Iandiev, I.; Wiedemann, P.; Reichenbach, A.; Bringmann, A. HB-EGF: Increase in the ischemic rat retina and inhibition of osmotic glial cell swelling. Biochem. Biophys. Res. Commun. 2006, 347, 310-318. [CrossRef]

49. Pannicke, T.; Frommherz, I.; Biedermann, B.; Wagner, L.; Sauer, K.; Ulbricht, E.; Hartig, W.; Krugel, U.; Ueberham, U.; Arendt, T.; et al. Differential effects of P2Y1 deletion on glial activation and survival of photoreceptors and amacrine cells in the ischemic mouse retina. Cell Death Dis. 2014, 5, e1353. [CrossRef]

50. Harada, T.; Harada, C.; Watanabe, M.; Inoue, Y.; Sakagawa, T.; Nakayama, N.; Sasaki, S.; Okuyama, S.; Watase, K.; Wada, K.; et al. Functions of the two glutamate transporters GLAST and GLT-1 in the retina. Proc. Natl. Acad. Sci. USA 1998, 95, 4663-4666. [CrossRef]

51. Pannicke, T.; Wurm, A.; Iandiev, I.; Hollborn, M.; Linnertz, R.; Binder, D.K.; Kohen, L.; Wiedemann, P.; Steinhauser, C.; Reichenbach, A.; et al. Deletion of aquaporin-4 renders retinal glial cells more susceptible to osmotic stress. J. Neurosci. Res. 2010, 88, 2877-2888. [CrossRef] [PubMed]

52. Li, J.; Patil, R.V.; Verkman, A.S. Mildly abnormal retinal function in transgenic mice without Muller cell aquaporin-4 water channels. Investig. Ophthalmol. Vis. Sci. 2002, 43, 573-579.

53. You, Y.; Zhu, L.; Zhang, T.; Shen, T.; Fontes, A.; Yiannikas, C.; Parratt, J.; Barton, J.; Schulz, A.; Gupta, V.; et al. Evidence of Muller Glial Dysfunction in Patients with Aquaporin-4 Immunoglobulin G-Positive Neuromyelitis Optica Spectrum Disorder. Ophthalmology 2019, 126, 801-810. [CrossRef] [PubMed]

54. McDowell, R.E.; Barabas, P.; Augustine, J.; Chevallier, O.; McCarron, P.; Chen, M.; McGeown, J.G.; Curtis, T.M. Müller glial dysfunction during diabetic retinopathy in rats is reduced by the acrolein-scavenging drug, 2-hydrazino-4,6-dimethylpyrimidine. Diabetologia 2018, 61, 2654-2667. [CrossRef]

55. Wagner, L.; Pannicke, T.; Rupprecht, V.; Frommherz, I.; Volz, C.; Illes, P.; Hirrlinger, J.; Jagle, H.; Egger, V.; Haydon, P.G.; et al. Suppression of SNARE-dependent exocytosis in retinal glial cells and its effect on ischemia-induced neurodegeneration. Glia 2017, 65, 1059-1071. [CrossRef]

56. Shah, M.; Cabrera-Ghayouri, S.; Christie, L.A.; Held, K.S.; Viswanath, V. Translational Preclinical Pharmacologic Disease Models for Ophthalmic Drug Development. Pharm. Res. 2019, 36, 58. [CrossRef]

57. Balaggan, K.S.; Binley, K.; Esapa, M.; MacLaren, R.E.; Iqball, S.; Duran, Y.; Pearson, R.A.; Kan, O.; Barker, S.E.; Smith, A.J.; et al. EIAV vector-mediated delivery of endostatin or angiostatin inhibits angiogenesis and vascular hyperpermeability in experimental CNV. Gene Ther. 2006, 13, 1153-1165. [CrossRef]

58. Fu, Z.; Gong, Y.; Liegl, R.; Wang, Z.; Liu, C.H.; Meng, S.S.; Burnim, S.B.; Saba, N.J.; Fredrick, T.W.; Morss, P.C.; et al. FGF21 Administration Suppresses Retinal and Choroidal Neovascularization in Mice. Cell Rep. 2017, 18, 1606-1613. [CrossRef]

59. Chakravarthy, U.; Walsh, A.C.; Muldrew, A.; Updike, P.G.; Barbour, T.; Sadda, S.R. Quantitative fluorescein angiographic analysis of choroidal neovascular membranes: Validation and correlation with visual function. Investig. Ophthalmol. Vis. Sci. 2007, 48, 349-354. [CrossRef] 
60. Berger, J.W.; Yoken, J. Computer-assisted quantitation of choroidal neovascularization for clinical trials. Investig. Ophthalmol. Vis. Sci. 2000, 41, 2286-2295.

61. Zhou, L.; Sun, X.; Huang, Z.; Zhou, T.; Zhu, X.; Liu, Y.; Wang, J.; Cheng, B.; Li, M.; He, C.; et al. Imatinib Ameliorated Retinal Neovascularization by Suppressing PDGFR-alpha and PDGFR-beta. Cell Physiol. Biochem. 2018, 48, 263-273. [CrossRef] [PubMed]

62. Schwarzer, P.; Kokona, D.; Ebneter, A.; Zinkernagel, M.S. Effect of Inhibition of Colony-Stimulating Factor 1 Receptor on Choroidal Neovascularization in Mice. Am. J. Pathol. 2020, 190, 412-425. [CrossRef] [PubMed]

63. Kleinman, M.E.; Yamada, K.; Takeda, A.; Chandrasekaran, V.; Nozaki, M.; Baffi, J.Z.; Albuquerque, R.J.; Yamasaki, S.; Itaya, M.; Pan, Y.; et al. Sequence- and target-independent angiogenesis suppression by siRNA via TLR3. Nature 2008, 452, 591-597. [CrossRef]

64. Huang, H.; Parlier, R.; Shen, J.K.; Lutty, G.A.; Vinores, S.A. VEGF receptor blockade markedly reduces retinal microglia/macrophage infiltration into laser-induced CNV. PLoS ONE 2013, 8, e71808. [CrossRef] [PubMed]

65. Tah, V.; Orlans, H.O.; Hyer, J.; Casswell, E.; Din, N.; Sri Shanmuganathan, V.; Ramskold, L.; Pasu, S. Anti-VEGF Therapy and the Retina: An Update. J. Ophthalmol. 2015, 2015, 627674. [CrossRef] [PubMed]

66. Rofagha, S.; Bhisitkul, R.B.; Boyer, D.S.; Sadda, S.R.; Zhang, K.; Group, S.-U.S. Seven-year outcomes in ranibizumab-treated patients in ANCHOR, MARINA, and HORIZON: A multicenter cohort study (SEVEN-UP). Ophthalmology 2013, 120, 2292-2299. [CrossRef] [PubMed]

67. Bhisitkul, R.B.; Desai, S.J.; Boyer, D.S.; Sadda, S.R.; Zhang, K. Fellow Eye Comparisons for 7-Year Outcomes in RanibizumabTreated AMD Subjects from ANCHOR, MARINA, and HORIZON (SEVEN-UP Study). Ophthalmology 2016, 123, $1269-1277$. [CrossRef]

68. Amadio, M.; Govoni, S.; Pascale, A. Targeting VEGF in eye neovascularization: What's new? A comprehensive review on current therapies and oligonucleotide-based interventions under development. Pharmacol. Res. 2016, 103, 253-269. [CrossRef]

69. Gasperini, J.L.; Fawzi, A.A.; Khondkaryan, A.; Lam, L.; Chong, L.P.; Eliott, D.; Walsh, A.C.; Hwang, J.; Sadda, S.R. Bevacizumab and ranibizumab tachyphylaxis in the treatment of choroidal neovascularisation. Br. J. Ophthalmol. 2012, 96, 14-20. [CrossRef]

70. Lambert, V.; Lecomte, J.; Hansen, S.; Blacher, S.; Gonzalez, M.L.; Struman, I.; Sounni, N.E.; Rozet, E.; de Tullio, P.; Foidart, J.M.; et al. Laser-induced choroidal neovascularization model to study age-related macular degeneration in mice. Nat. Protoc. 2013, 8, 2197-2211. [CrossRef]

71. Askou, A.L. Development of gene therapy for treatment of age-related macular degeneration. Acta Ophthalmol. 2014, 92, 1-38. [CrossRef] [PubMed]

72. Reid, C.A.; Nettesheim, E.R.; Connor, T.B.; Lipinski, D.M. Development of an inducible anti-VEGF rAAV gene therapy strategy for the treatment of wet AMD. Sci. Rep. 2018, 8, 11763. [CrossRef] [PubMed]

73. Guimaraes, T.A.C.; Georgiou, M.; Bainbridge, J.W.B.; Michaelides, M. Gene therapy for neovascular age-related macular degeneration: Rationale, clinical trials and future directions. Br. J. Ophthalmol. 2020. [CrossRef]

74. Slezak, M.; Goritz, C.; Niemiec, A.; Frisen, J.; Chambon, P.; Metzger, D.; Pfrieger, F.W. Transgenic mice for conditional gene manipulation in astroglial cells. Glia 2007, 55, 1565-1576. [CrossRef] [PubMed]

75. Luckoff, A.; Scholz, R.; Sennlaub, F.; Xu, H.; Langmann, T. Comprehensive analysis of mouse retinal mononuclear phagocytes. Nat. Protoc. 2017, 12, 1136-1150. [CrossRef]

76. Schneider, C.A.; Rasband, W.S.; Eliceiri, K.W. NIH Image to ImageJ: 25 years of image analysis. Nat. Methods 2012, 9, 671-675. [CrossRef]

77. Slezak, M.; Grosche, A.; Niemiec, A.; Tanimoto, N.; Pannicke, T.; Munch, T.A.; Crocker, B.; Isope, P.; Hartig, W.; Beck, S.C.; et al. Relevance of exocytotic glutamate release from retinal glia. Neuron 2012, 74, 504-516. [CrossRef]

78. Uckermann, O.; Iandiev, I.; Francke, M.; Franze, K.; Grosche, J.; Wolf, S.; Kohen, L.; Wiedemann, P.; Reichenbach, A.; Bringmann, A. Selective staining by vital dyes of Muller glial cells in retinal wholemounts. Glia 2004, 45, 59-66. [CrossRef]

79. Jeon, C.J.; Strettoi, E.; Masland, R.H. The major cell populations of the mouse retina. J. Neurosci. 1998, 18, 8936-8946. [CrossRef]

80. Pauly, D.; Agarwal, D.; Dana, N.; Schafer, N.; Biber, J.; Wunderlich, K.A.; Jabri, Y.; Straub, T.; Zhang, N.R.; Gautam, A.K.; et al. Cell-Type-Specific Complement Expression in the Healthy and Diseased Retina. Cell Rep. 2019, 29, 2835-2848. [CrossRef]

81. Rosenfeld, P.J.; Feuer, W.J. Lessons from Recent Phase III Trial Failures: Don't Design Phase III Trials Based on Retrospective Subgroup Analyses from Phase II Trials. Ophthalmology 2018, 125, 1488-1491. [CrossRef] [PubMed] 